\title{
Spatial Structure of Synchronized Inhibition in the Olfactory Bulb
}

\author{
Hannah A. Arnson and Ben W. Strowbridge \\ Department of Neurosciences, Case Western Reserve University, Cleveland, Ohio 44106
}

Olfactory sensory input is detected by receptor neurons in the nose, which then send information to the olfactory bulb (OB), the first brain region for processing olfactory information. Within the $\mathrm{OB}$, many local circuit interneurons, including axonless granule cells, function to facilitate fine odor discrimination. How interneurons interact with principal cells to affect bulbar processing is not known, but the mechanism is likely to be different from that in sensory cortical regions because the OB lacks an obvious topographical organization. Neighboring glomerular columns, representing inputs from different receptor neuron subtypes, typically have different odor tuning. Determining the spatial scale over which interneurons such as granule cells can affect principal cells is a critical step toward understanding how the $\mathrm{OB}$ operates. We addressed this question by assaying inhibitory synchrony using intracellular recordings from pairs of principal cells with different intersomatic spacing. We found, in acute rat $\mathrm{OB}$ slices from both sexes, that inhibitory synchrony is evident in the spontaneous synaptic input in mitral cells (MCs) separated up to $220 \mu \mathrm{m}\left(300 \mu \mathrm{m}\right.$ with elevated $\left.\mathrm{K}^{+}\right)$. At all intersomatic spacing assayed, inhibitory synchrony was dependent on $\mathrm{Na}^{+}$channels, suggesting that action potentials in granule cells function to coordinate GABA release at relatively distant dendrodendritic synapses formed throughout the dendritic arbor. Our results suggest that individual granule cells are able to influence relatively large groups of MCs and tufted cells belonging to clusters of at least 15 glomerular modules, providing a potential mechanism to integrate signals reflecting a wide variety of odorants.

Key words: brain slice; coincident inhibition; patch clamp; synaptic transmission

\section{Significance Statement}

Inhibitory circuits in the olfactory bulb $(\mathrm{OB})$ play a major role in odor processing, especially during fine odor discrimination. However, how inhibitory networks enhance olfactory function, and over what spatial scale they operate, is not known. Interneurons are potentially able to function on both a highly localized, synapse-specific level and on a larger, spatial scale that encompasses many different glomerular channels. Although recent indirect evidence has suggested a relatively localized functional role for most inhibition in the $\mathrm{OB}$, in the present study, we used paired intracellular recordings to demonstrate directly that inhibitory local circuits operate over large spatial scales by using fast action potentials to link GABA release at many different synaptic contacts formed with principal cells.

\section{Introduction}

Inhibitory local circuits play a central role in processing olfactory information. In insects, blockade of inhibitory function in the antennal lobe, the first processing region of olfactory information, impairs selectively the normal ability of the these animals to make fine distinctions between related similar odors while leav-

\footnotetext{
Received April 13, 2017; revised Aug. 22, 2017; accepted Sept. 14, 2017.

Author contributions: H.A.A. and B.W.S. designed research; H.A.A. performed research; H.A.A. and B.W.S. analyzed data; H.A.A. and B.W.S. wrote the paper.

This work was supported by the National Institutes of Health (Grant R01-DC04285 to B.W.S.). We thank Todd Pressler and Chris Ford for constructive comments on this manuscript.

The authors declare no competing financial interests.

Correspondence should be addressed to Dr. Ben W. Strowbridge, Department of Neurosciences, Case Western Reserve University School of Medicine, 10900 Euclid Avenue, Cleveland, OH 44106. E-mail: bens@case.edu. DOI:10.1523/JNEUROSCI.1004-17.2017

Copyright $\odot 2017$ the authors $\quad 0270-6474 / 17 / 3710468-13 \$ 15.00 / 0$
}

ing intact the ability to distinguish between unrelated olfactory stimuli (Stopfer et al., 1997). Recent work in the olfactory bulb (OB), the mammalian equivalent to the antennal lobe, has demonstrated parallel findings when selectively perturbing inhibition onto the principal neurons mitral cells (MCs) and tufted cells (TCs) (Abraham et al., 2010). These studies suggest that olfactory information can be processed through at least two distinct streams-either a hardwired pathway that does not require extensive local inhibitory interactions but which reveals only relatively coarse distinctions among odors or a more complex circuit involving functions mediated by inhibitory interneurons that facilitates fine distinctions. The latter pathway may also be a key site of olfactory learning within the bulb because previous work has found both LTP- and spike-timing-dependent plasticity on excitatory synapses onto granule cells, the primary type of GABAergic 
interneuron the OB (Gao and Strowbridge, 2009; Nissant et al., 2009). Granule cells also receive a large proportion of top-down and neuromodulatory input (Luskin and Price, 1983; Davis and Macrides, 1981), suggesting a role of behavioral state in regulating inhibition. However, how inhibitory interneurons such as GCs function to enhance olfactory performance is not known.

Recent experimental and computational studies of $\mathrm{OB}$ circuitry has led to two divergent views of GC function: (1) that GCs function through locally mediated inhibition with minimal integration of information across processing streams and (2) that GCs operate by interconnecting principal cells belonging to different sensory channels, enabling the circuit to represent more complex or abstract features than either MCs or TCs (Carey et al., 2015; Fukunaga et al., 2014; Arevian et al., 2008; McIntyre and Cleland, 2016). In the former model, GC function would likely enhance fine odor discrimination via actions on nearby principal cells belonging the same or close glomerular modules, whereas the latter models allows for extensive cross-channel synaptic interactions. Direct imaging of $\mathrm{Ca}^{2+}$ responses in GCs has demonstrated that olfactory stimuli appear to activate subregions within the apical dendritic arbor without strongly depolarizing the interneuron cell body (Wienisch and Murthy, 2016). These results are consistent with previous in vitro imaging and recording studies suggesting that that GC dendrites have the ability to generate spatially localized spikes (or spikelets; Egger et al., 2003, 2005; Zelles et al., 2006; Bywalez et al., 2015), providing a potential mechanism for highly localized MC/GC feedback inhibition. Other work supporting a spatially restricted role for GCs includes the observation that some forms of emergent network oscillations that appear to be dependent on GCs are not phase locked with somatic spiking in GCs (Lagier et al., 2004). Computational models of the circuits that could underlie these oscillations (Brea et al., 2009) support the hypothesis that the primary output mode of GCs is highly localized, perhaps restricted to a single GC spine or a small group of nearby spines on the same GC dendritic branch.

Because the GC dendritic arbor only spans a relatively narrow range of GL $(\sim 115 \mu \mathrm{m}$, representing two to four glomeruli; Dhawale et al., 2010; Ke et al., 2013; see Materials and Methods), alternate mechanisms that propose GCs operate across many glomerular columns depend on the ability of spiking activity to trigger GABA release at multiple synapses at remote locations within the dendritic arbor, triggering synchronized inhibitory responses in pairs of principal cells. Although long range, GC mediated inhibition has been shown to shape MC firing in response to distant MC activity (Arevian et al., 2008), direct recordings demonstrating synchronized inhibitory input over different spatial scales have been performed rarely and only under specialized conditions following tetanic electrical stimulation (Schoppa, 2006) or after pharmacological treatments that increase network excitability (Schmidt and Strowbridge, 2014). It is not known to what extent synchronized inhibition functions to couple principal cells under physiological conditions and if such synchronization is spike dependent.

Through paired intracellular recordings from OB principal cells, we demonstrated that inhibitory synchronization occurs frequently and is dependent on fast voltage-gated $\mathrm{Na}^{+}$channels. Divergent inhibitory inputs can functionally associate principal cells belonging to different subtypes (MCs and TCs) with somatic separations up to $300 \mu \mathrm{m}$, likely including principal cells belonging to at least 15 different glomerular columns. This study shows for the first time that inhibition can link a wide spatial range of glomerular columns in the absence of external synchronizing input, potentially providing a mechanism of how population codes for different odorants could be refined by local inhibitory circuits.

\section{Materials and Methods}

Slice preparation. Horizontal OB slices $300 \mu \mathrm{m}$ thick were made from ketamine-anesthetized postnatal day 14 (P14)-P25 Sprague Dawley rats of both sexes as described previously (Balu et al., 2007; Pressler et al., 2013). Slices were incubated for $30 \mathrm{~min}$ at $30^{\circ} \mathrm{C}$ and then at room temperature until use. All experiments were performed in accordance with the guidelines approved by the Case Western Reserve University Animal Care and Use Committee.

Electrophysiology. Slices were placed in a recording chamber and superfused with oxygenated artificial CSF (ACSF) at a rate of $1.5 \mathrm{ml} / \mathrm{min}$. Recordings were made between $29^{\circ} \mathrm{C}$ and $32^{\circ} \mathrm{C}$. ACSF consisted of the following (in mM): $124 \mathrm{NaCl}, 3 \mathrm{KCl}, 1.23 \mathrm{NaH}_{2} \mathrm{PO}_{4}, 1.2 \mathrm{MgSO}_{4}, 26$ $\mathrm{NaHCO}_{3}, 10$ dextrose, and $2.5 \mathrm{CaCl}_{2}$ equilibrated with $95 \% \mathrm{O}_{2} / 5 \% \mathrm{CO}_{2}$. The $\mathrm{K}^{+}$concentration was elevated in "high-K ASCF" by increasing the $\mathrm{KCl}$ concentration to $6 \mathrm{~mm}$. All whole-cell patch-clamp recordings were made with Axopatch 1C or 1D amplifiers (Molecular Devices) using borosilicate glass pipettes (WPI) of impedances ranging from 2 to $5 \mathrm{M} \Omega$ pulled on a P-97 pipette puller (Sutter Instruments). Recordings were low-pass filtered at $5 \mathrm{kHz}$ (FLA-01; Cygus Technology) and digitized at $10 \mathrm{kHz}$ using an ITC-18 computer interface (Instrutech) connected to a PC operating Windows 7 using custom software.

Slices were imaged using IR-DIC optics on Zeiss Axioskop FS1 or Olympus BX51WI upright microscopes. Live two-photon imaging was performed using a custom-built laser-scanning system, as described previously (Balu et al., 2007; Gao and Strowbridge, 2009; Pressler and Strowbridge, 2006). Neuronal cell type was determined based on IR-DIC morphology and soma laminar location. Cell type classification was confirmed in a subset of experiments using two-photon reconstructions as described in the Cellular Reconstructions section of the Methods. Somatic separation was measured using a calibrated eyepiece reticule. We used two-photon imaging to reconstruct the apical dendritic trees in four $\mathrm{MC} / \mathrm{MC}$ paired recordings, including three paired recordings that had above-chance coincident inhibition.

Voltage-clamp recordings were made with an internal solution containing the following (in mM): $140 \mathrm{CsCl}, 4 \mathrm{NaCl}, 10 \mathrm{HEPES}, 2$ EGTA, 4 MgATP, $0.3 \mathrm{Na}_{3}$ GTP, 10 phosphocreatine, and 5 QX-314 with a pH of 7.3 and an osmolarity of $290 \mathrm{mmol} / \mathrm{kg}$. The cesium-chloride solution was used to reverse the chloride gradient. Alexa Fluor 594 (10 $\mu \mathrm{M}$; Invitrogen) was added to the internal solution in experiments using live twophoton visualization. All drugs were purchased from Sigma-Aldrich except TTX, which was from Calbiochem, and gabazine, which was from Ascent. All drugs were prepared from aliquots stored at $-20^{\circ} \mathrm{C}$ except for TTX, which was prepared from a stock solution kept at $4^{\circ} \mathrm{C}$. The drugs were added to the bath by changing the external solution source.

Experimental design and statistical analysis. Spontaneous IPSCs were detected and measured automatically using a custom algorithm used in previous studies (Schmidt and Strowbridge, 2014; Larimer and Strowbridge, 2008; Larimer and Strowbridge, 2010; Hyde and Strowbridge, 2012). Detected events were confirmed by visual analysis. Event detection and data analysis routines were implemented in Python (version 3.5). Multiple trials (typically 10-20 episodes each lasting $10 \mathrm{~s}$; mean 16.9 trials) were acquired for each condition in each experiment. Summary data are presented as mean \pm SEM except where noted. Membrane variance was computed over $250 \mathrm{~ms}$ duration windows.

Cross-correlograms (examples are shown in Figs. 2D, 4D) were computed from the onset lags between all detected IPSC pairs and analyzed between -10 and $10 \mathrm{~ms}$ in $0.4 \mathrm{~ms}$ time bins. To determine statistical significance, the maximal cross-correlation value (averaged over 3 bins, $1.2 \mathrm{~ms}$ ) reported in the actual data was compared with surrogate data created by permuting inter-IPSC intervals. The mean of 100 interval permutation runs are presented in example cross-correlation plots (e.g., Fig. $2 D$, left, gray plot). The probability that the maximal crosscorrelation metric in the actual data was larger than expected by chance was computed empirically using three methods. In the first approach, we generated a distribution of 2000 maximal cross-correlation values from surrogate data in which the inter-IPSC intervals were permuted. For 
example, if the peak cross-correlation value obtained in one experiment was larger than 1900 of 2000 cross-correlation values obtained in the interval permutation runs, then the probability of inhibitory coincidence would be assigned as $0.05(100 / 2000)$. This analysis procedure was repeated five times for each experiment with the median recorded as the interval permutation-based $p$-value. Throughout the study, we express randomization-derived $p$-values as $-1{ }^{\star} \ln (\mathrm{P})$ where more positive numbers reflect lower $p$-values. The upper limit on this metric [7.6 $=-1 *$ $\ln (1 / 2000)]$ reflects experiments in which the peak cross-correlation values were lower in all randomization runs than in the actual (nonpermuted) dataset.

In the second randomization control method, we used trial shuffling to estimate whether each experiment had beyond-chance rates of inhibitory coincidence. In this test, we randomly selected different trials for cell A and for cell B from the same experiment, creating a dataset composed exclusively of nonsimultaneous records (e.g., trial 1 from cell A compared with trial 3 from cell B). This process was repeated 2000 times in each experiment to generate a $p$-value based on the distribution of trial shuffled recordings. As with the interval permutation control procedure, we repeated the trial-shuffling analysis five times and recorded the median of those runs as the trial shuffling-based $p$-value. Both the interval permutation and trial shuffling control procedures abolished the peak near $0 \mathrm{~ms}$ present in experiments with obvious inhibitory synchrony determined by visual inspection of raw intracellular records. Figures 2 and 4 illustrate cross-correlation plots after interval permutation and trial shuffling on two example paired recordings with frequent nearcoincident IPSCs.

Both interval permutation and trial-shuffling approaches generated similar metrics expressing the degree of inhibitory synchrony evident our primary dataset of 89 paired MC/MC recordings assayed under standard ACSF conditions $\left(r=0.92 ; p<10^{-30}\right.$; correlation performed on the $-\ln (\mathrm{P})$ metric as used throughout the study). We also computed a dual randomization $p$-value where we combined both randomization methods by computing bootstrap distributions based on interval permutations of trial shuffled data. Using a standard 0.05 threshold for statistical significance, the dual randomization $p$-value generated the most conservative ranking of inhibitory synchrony across experiments $(N=17 \mathrm{ex}$ periments with empirical $p$-values lower than this threshold compared with $N=21$ for the interval permutation approach and $N=23$ using only trial shuffling. Sixteen experiments had $p$-values $<0.05$ in all three randomization tests. Rather than report separate results from interval permutation and trial shuffling procedures, we only report only the final dual randomization $p$-value in the text and in the illustrations.

We set a threshold for statistical significance at 0.015 using the dual randomization $p$-value throughout the study. This value balanced competing goals of minimizing the false rejection rate while controlling the familywise error rate. A more conservative approach, such as Bonferroni corrections, would adjust the significance threshold to $0.05 / N$ where $N$ is the number of independent tests performed. This simple approach proved unworkable because the very low thresholds in our large $N$ dataset ( $p=0.00056$ for our population of $89 \mathrm{MC} / \mathrm{MC}$ paired recordings) rejected many experiments with obvious inhibitory coincidence and central peaks on cross-correlation plots that were abolished by both interval permutation and trial shuffling. As noted in other work, this approach often rejects true positives and therefore tends to reduce statistical power (Gelman et al., 2012). Using a Bonferroni correction approach also would lead to different thresholds for statistical significance across the different groups of experiments. The empirical $p$-value approach that we followed has been used in previous studies (Sham and Purcell, 2014; Westfall, 2011; Westfall and Young, 1993; Narayanan and Laubach, 2009) and allowed us to specify a uniform threshold (0.015) that was more stringent than the $p$-value traditionally used with single tests (0.05). Using all three randomization approaches, we found a large drop-off in $p$-values near this threshold (from $<0.0101$ in all experiments labeled significant to 0.042 in the best experiment labeled as nonsignificant). In our primary dataset with 89 paired MC/MC recordings, using this threshold resulted in 16 experiments with significant inhibitory synchrony. In Figure $2 E$, we also estimated the degree of inhibitory synchrony using the clipped cross-intensity function approach (CIF; Hahnloser, 2007) that we have used in a related study (Schmidt and Strowbridge, 2014). This metric was based on the count of near-coincident IPSPs (onset times within $3 \mathrm{~ms}$ ) divided by the total number of IPSCs in the cell with the fewest IPSCs. As with the cross-correlation method, we computed $p$-values for each experiment empirically based on a distribution of CIF metrics generated in surrogate data in which inter-IPSC intervals were permuted.

The estimates of the rates of above-chance inhibitory coincidence presented in Figure $7 D$ were computed by subtracting the rates of nearcoincident IPSCs (onset latencies within $3 \mathrm{~ms}$ ) before and after trial shuffling. We plotted the rate of near-coincident IPSCs beyond expected by chance as a percentage of the TTX-sensitive IPSC rate in each cell. For example, if the actual rate of near-coincident IPSCs was $2 \mathrm{~Hz}$ which then dropped to $0.5 \mathrm{~Hz}$ after trial shuffling, then the rate of "beyond-chance" near-coincident IPSCs would be $1.5 \mathrm{~Hz}$. If the spike-dependent rate of spontaneous IPSCs was $15 \mathrm{~Hz}$ in one of the cells in the paired recording (reflecting $20 \mathrm{~Hz}$ spontaneous IPSCs recorded in ACSF and $5 \mathrm{~Hz}$ in TTX), then "beyond chance" coincident IPSCs would constitute $10 \%$ of the spike-driven spontaneous IPSCs in that neuron.

Cellular reconstructions. The horizontal span of the GC dendritic arbor was calculated from 19 published GC reconstructions shown in the following figures: Figure 2 in Price and Powell (1970); Figures 1C, $2 A, 2 \mathrm{H}$, and $3 A$ in Burton and Urban (2015); Figure 2 in Egger et al. (2005); Figure 1 in Wellis and Scott (1990); Figures 4A, 5A, and $6 A$ in Woolf et al. (1991); and Figure $1 M-O$ in Petreanu and Alvarez-Buylla (2002). To account for shrinkage during fixation, the measured width was increased by $15 \%$ (Tukker et al., 2013; Korogod et al., 2015). The mean GC dendritic width that we estimated from these published studies was $113 \pm$ $11.1 \mu \mathrm{m}$ with a SD of $48.5 \mu \mathrm{m}$.

We estimated the thickness of the GL in $10 \mathrm{OB}$ slices visualized using a $5 \times$ objective $(185 \pm 21 \mu \mathrm{m}$; mean $\pm \mathrm{SD})$. We estimated the glomerular packing density using our measured GL thickness and the mean glomerular diameter reported in two anatomical studies ( $75 \mu \mathrm{m}$; Dhawale et al., 2010; Ke et al., 2013). The horizontal span of MC lateral dendrites was estimated from maximal two-photon $Z$-stack projections $(N=33$ lateral dendrites from 21 visualized MCs; $349 \pm 180 \mu \mathrm{m}$; mean \pm SD. The actual length of the lateral dendrites was $\sim 10 \%$ larger than the horizontal span (the component of distance within the mitral cell layer, MCL), reflecting angled trajectory of these dendrites from the cell body into the external plexiform layer (EPL).

\section{Results}

We divided our analysis of inhibitory input onto principal cells in this study into two sections, starting with determining the properties of spontaneous ISPCs in MCs and TCs (Fig. 1) and then focusing on measuring coincident inhibition across pairs of intracelluarly recorded principal cells to assess the spatial scale of inhibitory synchrony in the OB (Figs. 2-7). Both MCs and TCs receive frequent spontaneous IPSCs, shown as inward currents in the example voltage-clamp recordings in Figure 1, $A$ and $B$, which used CsCl-based intracellular solutions that reversed the normal chloride gradient. Spontaneous inwards currents were abolished by the GABA-A receptor antagonist gabazine (10 $\mu \mathrm{M} ; 96.6 \%$ reduction in membrane current variance; Fig. $1 C$ ), indicating that spontaneous IPSCs form the majority of the detectable synaptic input onto OB principal cells under these recording conditions. Most of the detected IPSCs in MCs appeared to originate from synapses onto secondary dendrites and not from synapses onto the distal apical dendrite. In a subset of $21 \mathrm{MCs}$ visualized using live two-photon microscopy, we found only a small decrease in the rate of spontaneous IPSCs in MCs with apical dendrites truncated before they reached the GL $(12.7 \pm 1.5 \mathrm{~Hz} ; N=$ 15) compared with MCs with intact apical dendrites (14.6 \pm 1.6 $\mathrm{Hz} ; N=6: p=0.49$; unpaired $t$ test; mean \pm SEM).

We first compared the baseline frequency and amplitude of inhibitory inputs onto both classes of principal cells. MCs received a significantly higher rate of spontaneous IPSCs than TCs 
A

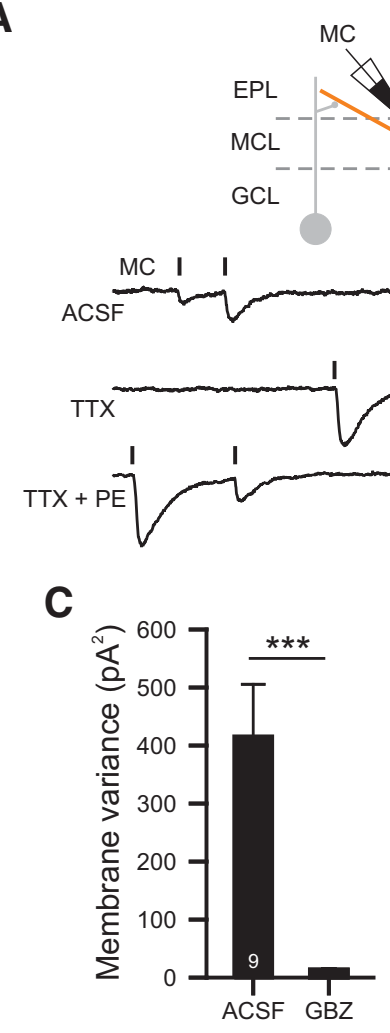

B
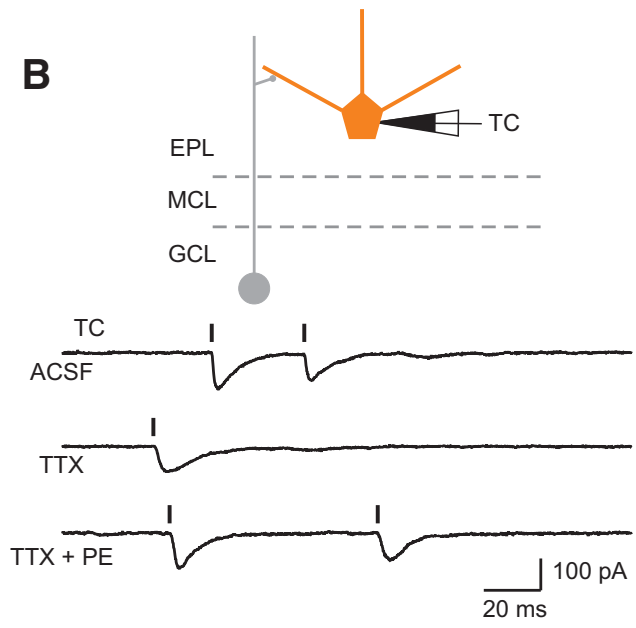

$\mathbf{E}$

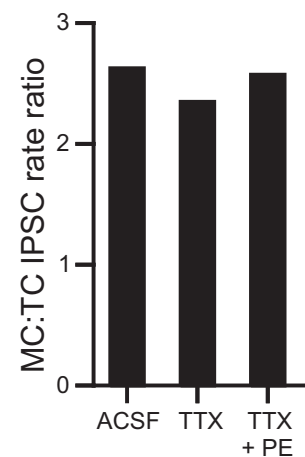

\section{$\mathbf{F}$}

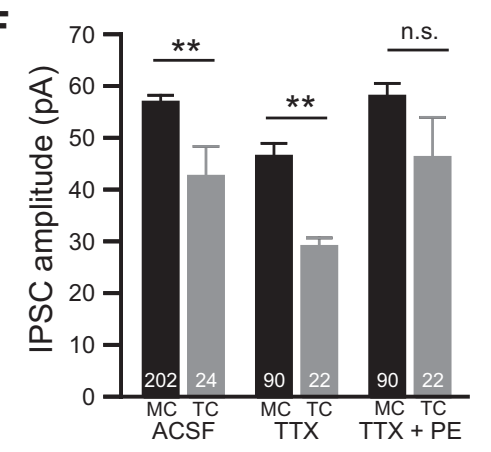

G

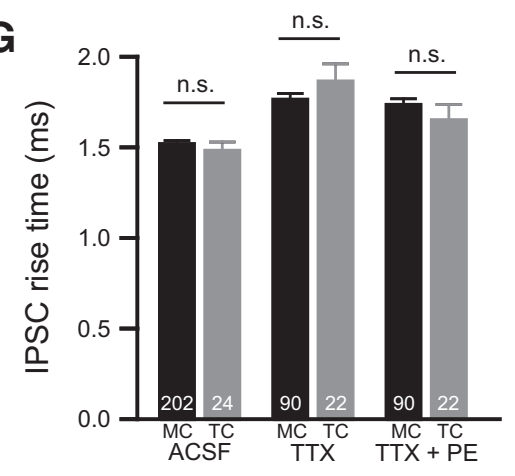

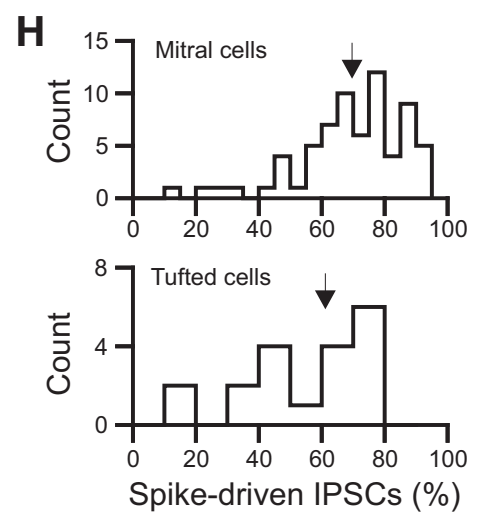

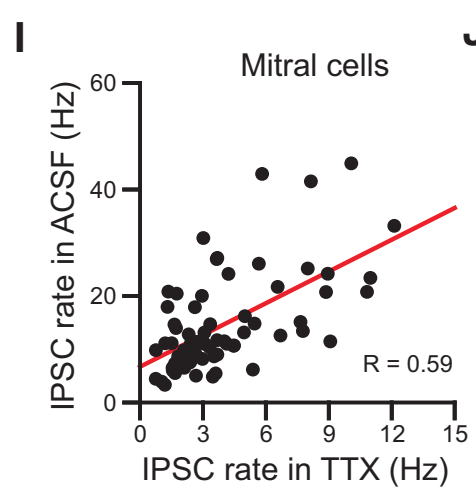

$\mathbf{J}$

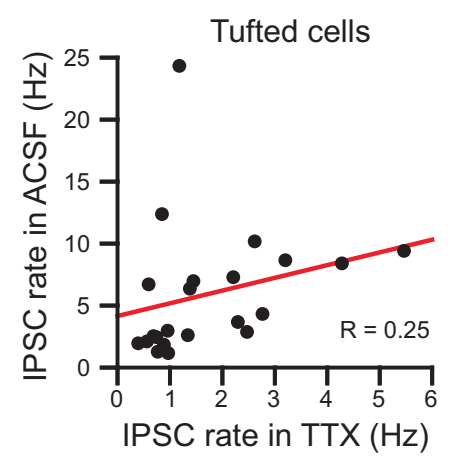

Figure 1. Inhibitory input to MCs and TCs. A, Example records of spontaneous IPSCs in ACSF (top), TTX (1 $\mu$ M; middle) and TTX + PE (phenylephrine; $10 \mu M$; bottom trace). Diagram of recording configuration is shown above traces. Vertical lines indicate automatically detected IPSC onset times. B, Example recording illustrating spontaneous IPSCs recorded in a TC under the same conditions as $\boldsymbol{A}$. $\boldsymbol{C}$, Plot of reduction of membrane current noise (variance) by $10 \mu \mathrm{M}$ gabazine in 9 experiments ( $N=5 \mathrm{MCs}$ and $4 \mathrm{TCS}){ }^{* * *} p=0.003$; paired $t$ test; $t_{(8)}=4.2$. The reduction in gabazine was also statistically significant when MCs and TCs were analyzed separately (MCs: $p=0.015 ; \mathrm{TCs}: p=0.029)$. $\boldsymbol{D}$, Plot of spontaneous IPSC rate in MCs (black bars) and TCs (gray bars) in ACSF, TTX, and TTX + PE. TC/MC comparisons ${ }^{* * *} p=7.6 \times 10^{-6}$ (ACSF; unpaired $t$ test; $\left.t_{(224)}=4.58\right), p=1.99 \times 20^{-4}\left(\mathrm{TTX} ; t_{(110)}=3.85\right), p=6.11 \times 10^{-5}\left(\mathrm{TTX}+\mathrm{PE} ; t_{(110)}=4.17\right)$. Within each cell type, IPSC rates were lower in TTX than ACSF (MCs: $p=10^{-21}$; TCs: $p=0.0014$; paired $t$ test) but not different between ACSF and TTX + PE conditions (Figure legend continues.) 
(Fig. $1 D, E$ ), consistent with results from a recent comparison of bulbar neurons (Geramita et al., 2016). The mean IPSC amplitude was modestly smaller in TCs than MCs (Fig. $1 F$ ), whereas the rising-phase kinetics were similar in both cell types (Fig. 1G). In both cell types, blockade of voltage-gated $\mathrm{Na}^{+}$channels with 1 $\mu \mathrm{M}$ TTX dramatically decreased spontaneous ISPC frequency (Fig. 1D, middle), suggesting that most synaptic responses resulted from $\mathrm{Na}^{+}$-based spiking in GCs or other classes of GABAergic interneurons. Enhancing GC excitability by stimulating $\alpha$-adrenegic receptors with phenylephrine (PE; $10 \mu \mathrm{M})$ (McLennan, 1971; Salmoiraghi et al., 1964; Araneda and Firestein, 2006; Zimnik et al., 2013) was able to restore basal IPSC rates in both principal cell types even in the presence of TTX (Fig. 1D, right).

Surprisingly, throughout these manipulations, the ratio of spontaneous IPSC frequencies between MCs and TCs remained relatively constant (Fig. 1E), suggesting that the two cell types differed primarily in the density of inhibitory connections with GCs. The proportion of spike-driven IPSCs also was similar in both cell types (mean of $70 \%$ in MCs vs $61 \%$ in TCs; Fig. $1 H$ ). We observed a strong correlation between miniature IPSC rates and basal spontaneous IPSC rates that was more pronounced in MCs (Fig. $1 I ; r=0.59 ; p=10^{-7}$ ) than TCs (Fig. $1 J$ ). As with the other measures of inhibitory function, we found more variability among TC IPSC rates, including an outlier recording with very high spontaneous IPSC rates. Excluding this outlier TC, the correlation between miniature IPSC rates and basal spontaneous IPSC rates was statistically significant $(r=0.532, p=0.013 ; r=$ 0.251 including outlier value). Together, these results suggest that the basal inhibitory synaptic tone in MCs and TCs is determined primarily by the density of GABAergic synapses on the secondary dendrites (and potentially somatic sites). Both cell types likely sample from similar pools of spontaneously active interneurons, accounting for the similar properties of individual IPSCs in MCs and TCs, the similar fraction of TTX-sensitive IPSCs, and the ability of miniature IPSC rates to predict the basal spontaneous IPSC rates. The difference in inhibitory synaptic tone that we and others (Geramita et al., 2016) have observed in OB principal cells likely reflects fewer synaptic contacts on TCs versus MCs, consistent with previous anatomical studies (Mori et al., 1983; Orona et al., 1984).

\section{Coincident inhibition between pairs of $\mathrm{OB}$ principal cells}

After determining baseline properties of spontaneous IPSCs in MCs and TCs, we next recorded from pairs of principal cells $(N=$ $89 \mathrm{MC} / \mathrm{MC}$ and $24 \mathrm{MC} / \mathrm{TC}$ ) separated by variable distances to determine the spatial scale of over which synchronized inhibition occurs in the OB. A subset $(\sim 15 \%)$ of paired MC recording had

\section{$\leftarrow$}

(Figure legend continued.) (MCs: $p=0.54, \mathrm{TCs}: p=0.80)$. $\boldsymbol{E}$, Plot of ratio of IPSC rates in MCs and TCs under the same three conditions. $F$, Plot of mean IPSC amplitude in MCs and TCs. ${ }^{* *} p=$ 0.0022 (ACSF; unpaired $t$ test; $\left.t_{(224)}=3.10\right), p=0.0015\left(\right.$ TTX; $t_{(110)}=3.26$ ), TTX + PE: N.S. $p=0.073$. Mean IPSC amplitude also was different between ACSF and TTX conditions in MCs (unpaired $t$ test; $\left.p=1.8 \times 10^{-4} ; t_{(290)}=3.8\right)$ and TCs $\left(p=0.043 ; t_{(44)}=2.1\right)$ ), but not between ACSF and TTX + PE conditions (MCs: $p=0.67 ; \mathrm{TCs} p=0.71$ ). G, Plot of mean IPSC rise times in the same conditions ( $p>0.05$ in all comparisons between conditions and between MCs and TCs in the same condition). $\boldsymbol{H}$, Histogram of percentage of TTX-sensitive (spike-driven) IPSCS compared with the IPSC rate in ACSF in $68 \mathrm{MCs}$ and $22 \mathrm{TCs}$. Arrows indicate population means (MCs: 69.6\%; TCs: 61.1\%). I, Plot of the relation between miniature (TTX-resistant) and spontaneous IPSC rates in $68 \mathrm{MCS}$ (Pearson correlation $r=0.59 ; p=1 \times 10^{-7}$ ).J, Similar plot for 24 TCs $(r=0.25 ; p=0.25)$. In all subsequent figures, ${ }^{*} p<0.05 ;{ }^{* *} p<0.01 ;{ }^{* * *} p<$ 0.005 . multiple coincident IPSCs evident by visual inspection of intracellular records, such as the example paired recording in Figure 2, $A-C$. We used two independent control procedures to determine whether the rate of coincident IPSCs was greater than expected by chance in each paired $\mathrm{MC} / \mathrm{MC}$ recording. We first computed the cross-correlation based on IPSC onset times in both cells and compared the maximal cross-correlation function ("actual") to randomized data in which the intervals between recorded IPSCs were permuted ("interval permutation"; Fig. 2D, left). In the second analysis method, we compared the maximal cross-correlation function computed from actual data with the same analysis performed trial shuffled recorded (Fig. 2D, right; see Materials and Methods), generating a dataset with physiological IPSC timing statistics but no actual coincidences because only nonsimultaneously recorded datasets were analyzed (e.g., trial 1 from MC-A with trial 2 from MC-B). We computed the probability that actual maximal cross-correlation function was larger than expected by chance by combining the interval permutation and trial-shuffling procedures 2000 times; the threshold for significance used was $p<0.015$; see Materials and Methods for details). Sixteen of $89 \mathrm{MC} / \mathrm{MC}$ paired recordings met this criterion for above-chance rates of near-coincident IPSCs. All $16 \mathrm{MC} / \mathrm{MC}$ paired recordings identified as having inhibitory synchronization assayed through the cross-correlation method also exhibited statistically significant rates of coincident IPSCs when tested using the cross-intensity function method used in previous work (Fig. 2E; Schmidt and Strowbridge, 2014).

Near-coincident synaptic inputs identified by our analysis (which captured onset latencies that differed by up to $20 \mathrm{~ms}$ ) were nearly synchronous in the subgroup of $16 \mathrm{MC} / \mathrm{MC}$ paired recording classified as statistically significant. The mean latency between IPSC onset times across the two cells was $0.05 \pm 0.13 \mathrm{~ms}$ (range -1.0 to $1.4 \mathrm{~ms} ; N=16$ experiments; histogram shown in Fig. $2 F$ ). There was no difference between the overall mean IPSC rates in the 16 significant MC/MC paired recordings and the other 73 paired recordings (Fig. 2G). The inhibitory synchrony we observe was unlikely to arise from glomerular-layer local circuits because three of the 16 significant $\mathrm{MC} / \mathrm{MC}$ paired recordings included least one MC with a truncated apical dendrite, reducing the contributions from GL interneurons (example shown in Fig. $2 A-C$ ). All three of the paired recordings that included MCs with truncated apical dendrites had highly significant inhibitory synchrony $\left(p<5 \times 10^{-4}\right.$, the lowest possible $p$-value in our bootstrap analysis; somatic separations of 50,50 , and $80 \mu \mathrm{m}$ ), suggesting that coincident inhibitory input does not originate from GL interneurons.

We determined the spatial scale of coincident inhibition by plotting the $p$-value computed from the interval permutation analysis against the separation between the two MC somata (Fig. $3 A, B)$. Most MC/MC paired recordings with significant inhibitory synchrony occurred between closely spaced neurons (intersoma distances $<100 \mu \mathrm{m}$ ). The maximal somatic separation that generated inhibitory synchrony beyond chance levels in standard ACSF was $220 \mu \mathrm{m}$. When restricted to intersomatic spacing $<220 \mu \mathrm{m}$, we still observed no difference in the mean IPSC rate between significant and nonsignificant MC/MCs pairs $(p=0.71$; unpaired $t$ test; $\left.t_{(57)}=0.38\right)$, suggesting that our metric of inhibitory synchrony was not simply revealing an underlying bias toward MCs with high (or low) spontaneous IPSC rates. The distribution of $p$-values estimated from interval permutation in trial-shuffled data (all $<0.015$; Fig. $3 B$, right; equivalently, $>4.2$ on the scale in Fig. $3 B$ ) was similar to the distribution of the actual nonsignificant MC/MCs (non-trial-shuffled data; Fig. 3B, left, 


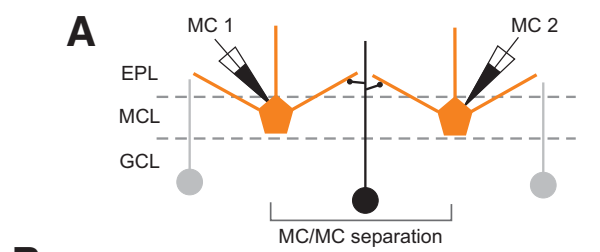

B

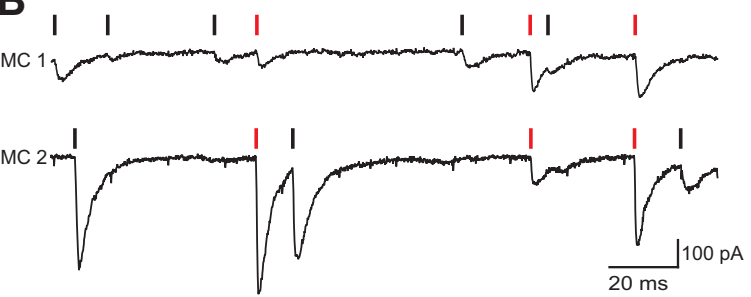

D
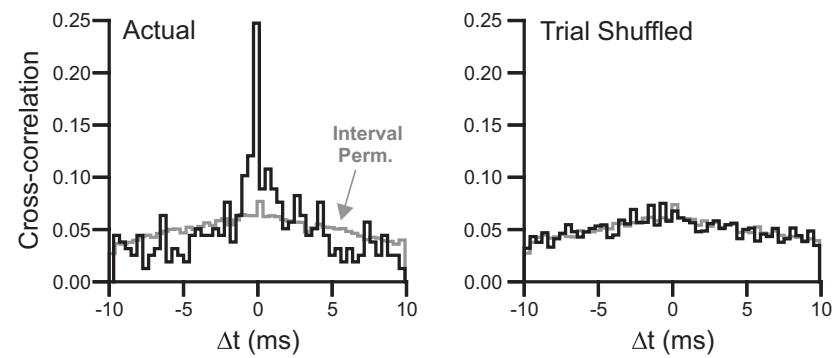

E

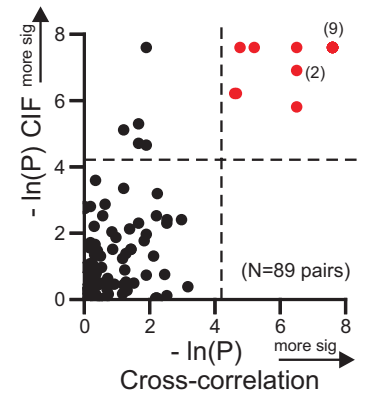

F
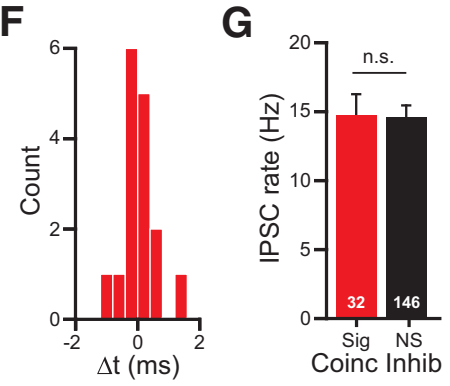

Figure 2. Coincident inhibitory input onto MCs. $\boldsymbol{A}$, Diagram of dual MC recording configuration. $\boldsymbol{B}$, Example simultaneous intracellular recording from two MCs. Near-coincident IPSPs (onset lags: $-0.1,-0.1$ and $-0.1 \mathrm{~ms}$ ) marked by red vertical lines; other automatically detected IPSCs indicated by black lines. $\boldsymbol{C}$, Two-photon reconstruction of the two MCs shown in $\boldsymbol{B}$. Both MCs had apical dendrites that were truncated (red arrowheads) before reaching the GL. D, Plot of cross-correlation of actual (left) and trial shuffled (right; mean of 100 runs) IPSCs times in experiment shown in $\boldsymbol{B}$. Gray traces show chance rate of near-coincident IPSCS estimated from interval permutation in both datasets (actual and trial shuffled; plot represents mean of 100 interval permutation runs). $\boldsymbol{E}$, Plot of the relationship between degree of inhibitory synchrony between MC/MC pairs estimated from the crosscorrelation method shown in $\boldsymbol{D}$ (the dual randomization $p$-value described in the Materials and Methods) and the clipped CIF. The probability of near-coincident inhibition increases with higher numbers; axes reflect $-1{ }^{*}$ natural $\log (p$-value). Red symbols reflect $p<0.015 ; 4.2=-1{ }^{*} \ln (0.015)$. Multiple experiments with similar $p$-values are indicated by " $(n)$." $\boldsymbol{F}$, Histogram of IPSC lag corresponding to maximal cross-correlation in $16 \mathrm{MC} / \mathrm{MC}$ paired recordings with statistically significant inhibitory synchrony (0.4 ms bins). G, Comparison of mean IPSC rates in MC/MC pairs with (red) and without (black) inhibitory synchrony ( $p=0.94$; unpaired $t$ test).

black symbols). These results suggest that our dataset of MC/MC paired recordings comprised two populations: a minority (18\%) that received coincident inhibition, presumably reflecting divergent output from one or more spontaneously spiking interneurons, and $\mathrm{MC} / \mathrm{MC}$ pairs that received no detectable inhibitory coincidence.

Although most of the MC/MC pairs we found that have above-chance rates of coincident IPSCs were relatively closely spaced (mean somatic separation $80.0 \pm 14.7 \mu \mathrm{m} ; N=16$ pairs), this estimate is biased toward nearby pairs because of slice truncation effects; relatively short-range divergent projections from one interneuron are more likely to be preserved within $300 \mu \mathrm{m}$ thick $\mathrm{OB}$ slices than longer range projections. Therefore, the most biologically relevant parameter reflecting the spatial scale of coincident inhibition is likely to be the furthest extent over which we can detect coincident inhibition. This parameter (up to $220 \mu \mathrm{m} \mathrm{MC} \mathrm{somatic}$ separation) suggests that individual interneurons can couple MCs associated with different glomeruli (mean glomerular diameter $75 \mu \mathrm{m}$; Dhawale et al., 2010; $\mathrm{Ke}$ et al., 2013). We confirmed this was possible by recording and visualizing two MCs with intact apical dendritic tufts that terminated in nearby but different glomeruli (Fig. 4A-C; intersoma distance $40 \mu \mathrm{m}$, apical dendritic tufts separated by $130 \mu \mathrm{m})$. The cross-correlation function in this paired recording (Fig. $4 D$, left; $p=0.0005$ ) had a peak at $0.2 \mathrm{~ms}$.

Under basal (unstimulated) conditions, we also observed inhibitory synchrony between heterogeneous pairs of principal cells (experiments including one $\mathrm{MC}$ and one TC recording; Fig. 5A). Figure $5 B$ illustrates an example of coincident IPSCs recorded in a MC/TC pair with intersoma spacing of $80 \mu \mathrm{m}$ (measured as the horizontal distance through the MCL ignoring the different distances in the MCL-to-GL direction). Using the same criteria applied to $\mathrm{MC} / \mathrm{MC}$ paired recordings, three of 24 $\mathrm{MC} / \mathrm{TCs}$ had statistically significant inhibitory coincidence (Fig. 5C), including the example recording presented in Figure $5 B$. The three significant MC/TC pairs were separated by between 20 and $150 \mu \mathrm{m}$ (span along the MCL). The mean somatic separation in the $3 \mathrm{MC} / \mathrm{TC}$ pairs with coincident inhibition was $86.7 \pm 33.1 \mu \mathrm{m}$. The mean latency between near-coincident IPSCs was $0.2 \pm 0.33 \mathrm{~ms}$ (range, -0.2 to $1 \mathrm{~ms}$ ). As with the MC/MC paired recording that showed elevated rates of near-coincident IPSCs, there was no difference in the mean IPSC rates between $\mathrm{MC} / \mathrm{TC}$ pairs with and without demonstrable inhibitory synchrony $(p=0.09$; unpaired $t$ test). These results suggest that not all inhibitory local circuits in the $\mathrm{OB}$ are segregated into MC- and TCspecific subgroups. Instead, individual GCs or EPL interneurons (Kato et al., 2013) appear to innervate both populations of principal cells.

\section{Spike-dependent inhibitory synchrony}

We next investigated whether near-coincident IPSCs recorded in pairs of principal cells required $\mathrm{Na}^{+}$-based action potentials in the common presynaptic interneurons. Bath application of TTX $(1 \mu \mathrm{M})$ abolished inhibitory synchrony in all $16 \mathrm{MC} / \mathrm{MC}$ pairs with statistically significant rates of near-coincident IPSCs (Fig. $5 D)$. No previously nonsignificant paired recording experiments became significant through this treatment. The loss of inhibitory synchrony did not simply reflect the lower overall rate of spontaneous IPSCs in TTX because addition of the GC-stimulating $\alpha$ 
receptor agonist PE (10 $\mu \mathrm{M}$; McLennan, 1971; Salmoiraghi et al., 1964; Araneda and Firestein, 2006; Zimnik et al., 2013) failed to promote synchronous inhibition in MC paired recordings (Fig. $4 D ; 0 / 44$ experiments). We found similar results in heterogeneous MC/TC pairs in which TTX abolished inhibitory synchrony in the three paired MC/TC recordings with statistically significant rates of near-coincident IPSCs (Fig. 4E). Because voltage-gated $\mathrm{Na}^{+}$channels were already blocked in MC and TC voltage-clamp recordings (because of QX-314 in the internal solution), these results suggest that synchronous IPSCs resulted from spontaneous spiking in GABAergic interneurons that form divergent synaptic connections onto $\mathrm{MC}$ and $\mathrm{MC} / \mathrm{TC}$ ensembles.

If near-coincident IPSCs recorded in pairs of principal cells reflect spontaneous spiking in presynaptic GABAegic interneurons, we hypothesized that passively depolarizing interneurons by elevating extracellular $\mathrm{K}^{+}$concentration (from 3 to $6 \mathrm{~mm}$; "high-K" ACSF) would enhance inhibitory synchrony. The relatively weak passive depolarization produced by this treatment, estimated to shift the $\mathrm{K}^{+}$equilibrium potential by $+18 \mathrm{mV}$, did not preclude repetitive firing in 3/3 GCs tested (AP amplitude reduced by $3.5 \pm 0.5 \mathrm{mV}$ and $\mathrm{AP}$ full width increased by $0.39 \pm$ $0.04 \mathrm{~ms}$ in $6 \mathrm{mM} \mathrm{K}^{+}$). As shown in the example records in Figure $6 A$, high-K ACSF increased both the rate of spontaneous IPSCs in MCs and also the incidence of nearcoincident IPSCs. Of the 19 paired MC experiments in high-K ACSF, nine (47\%) had statistically significant inhibitory synchrony, including the paired recording shown in Figure 6A. Two of the nine significant $\mathrm{MC} / \mathrm{MC}$ recordings already had significant rates of inhibitory synchrony in control conditions before treatment with high-K ACSF (Fig. 6B). In the remaining seven significant $\mathrm{MC} / \mathrm{MC}$ recordings, no inhibitory synchrony was evident except in high-K ACSF. The mean IPSC latency in the $9 \mathrm{MC}$ paired recordings with near-coincident IPSCs in high-K ACSF was $0.24 \pm 0.19 \mathrm{~ms}$ (range -0.6 to $1.4 \mathrm{~ms}$ ). The ability of slightly elevated $\mathrm{K}^{+}$levels to increase the frequency that we observed coincident inhibition suggests that, under physiological conditions $\left(3 \mathrm{~mm}\left[\mathrm{~K}^{+}\right]\right)$, the slow rate of GC spontaneous spiking limits our ability to detect synchronous inhibition.

Our results thus far demonstrated divergent effects of passive depolarization with high-K ACSF, which promoted inhibitory synchrony, and activation of adrenergic receptors with $\mathrm{PE}$, which stimulated GABA release (increasing miniature IPSC rates), but did not trigger more frequent coincident IPSCs. Consistent with this model, PE combined with high-K ACSF increased spontaneous IPSC rates (Fig. 6C) but abolished most inhibitory synchrony (only 1/10 experiments with $\mathrm{PE}+$ high-K ACSF has statistically significant inhibitory synchrony; Fig. 6D). As with our earlier results suggesting a requirement for $\mathrm{Na}^{+}$-based action potentials, inhibitory synchrony present in high-K ACSF was abolished in TTX (Fig. 6D; zero of nine experiments including
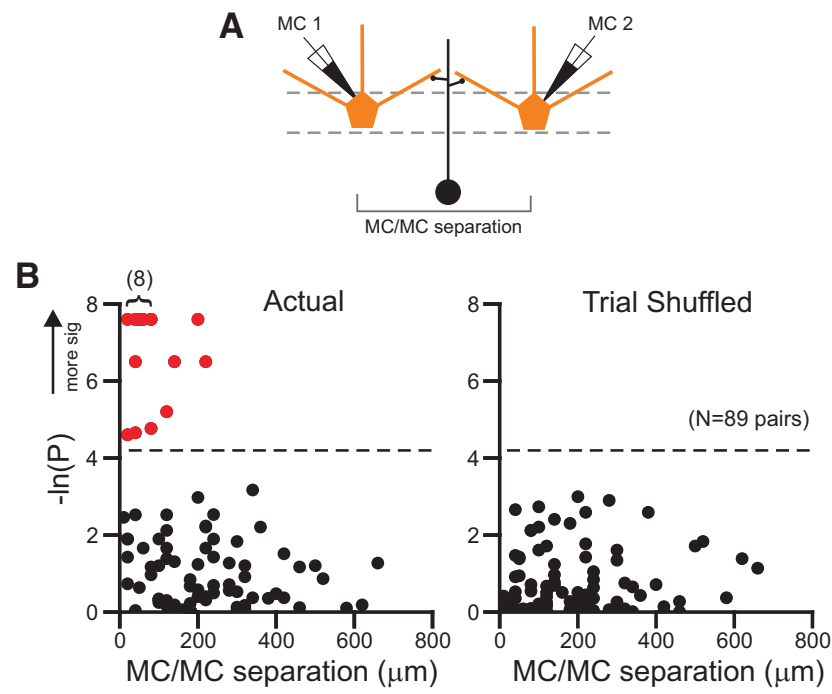

Figure 3. Spatial scale of coincident inhibition among MCs. $A$, Diagram of dual MC recording configuration. $\boldsymbol{B}$, Plot of the probability of inhibitory coincidence versus separation between $M C$ somata in 89 experiments from actual IPSC timing (left) and after trial shuffling (right). Red symbols indicate $p<0.015$ ( $>4.2$ on $-1 * \ln (P)$ axis; dashed line). Cluster of red dots marked " $(8)$ " in left plot corresponds to 8 experiments with similar $p$-values.
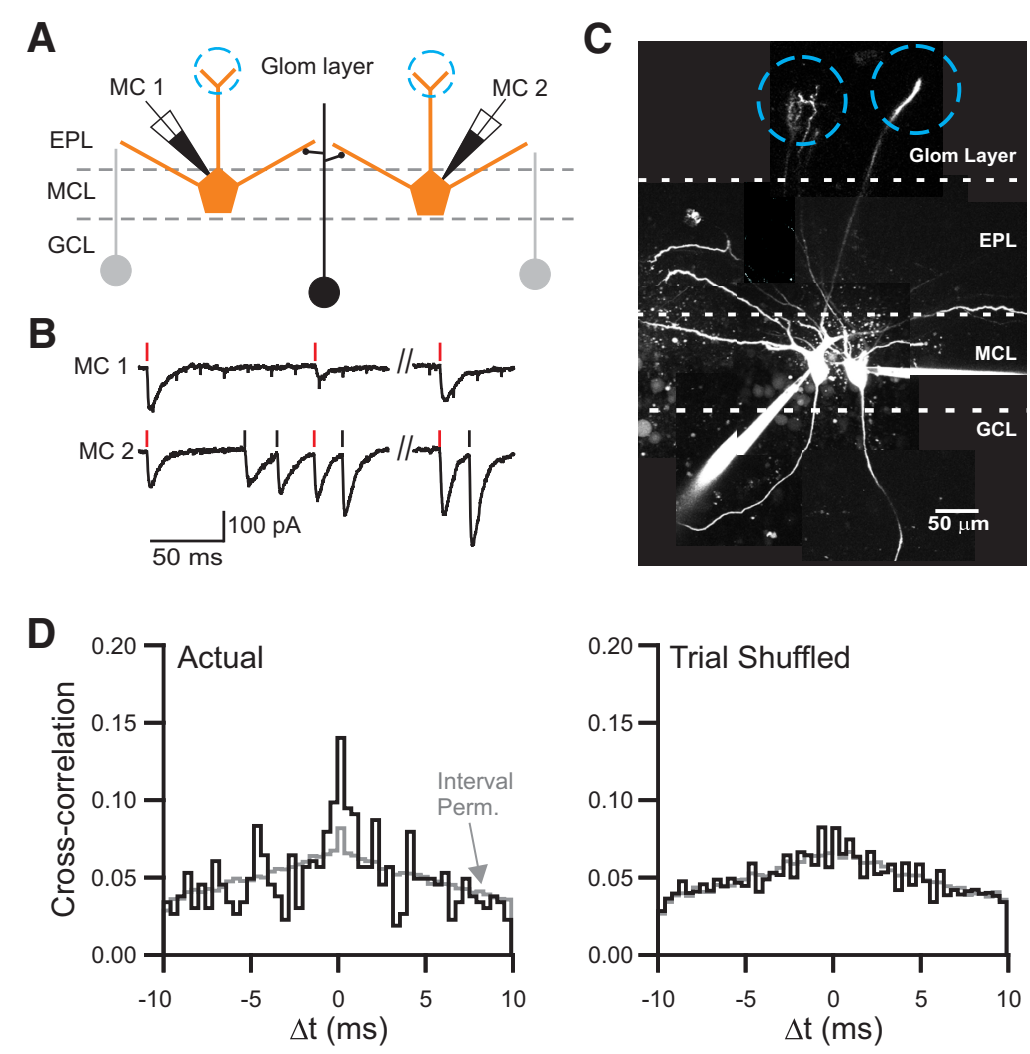

Figure 4. Coincident inhibition in MCs belong to different glomeruli. $A$, Diagram of recording configuration. $B$, Example recording from two MCs with near-coincident IPSCs (onset lags: $-0.1,-0.6$, and $-0.2 \mathrm{~ms}$ ). C, Two-photon reconstruction of the two MCs shown in $\boldsymbol{B}$. The apical dendrites terminated in different glomeruli separated by $130 \mu \mathrm{m}$ (indicated by blue circles). $\boldsymbol{D}$, Plot of cross-correlation in the MC/MC pair shown in $\boldsymbol{B}$ and $\boldsymbol{C}$ based on actual (left) and trial-shuffled (right; mean of 100 trial shuffling runs) IPSC onset times. Gray traces show the shift predictor estimated from interval permutation (100 interval permutation runs).

three MC paired recordings that had statistically significant inhibitory synchrony in high-K ACSF).

Although high-K ACSF did not affect the amplitudes of spontaneous IPSCs recorded in MCs, PE triggered a modest but sta- 

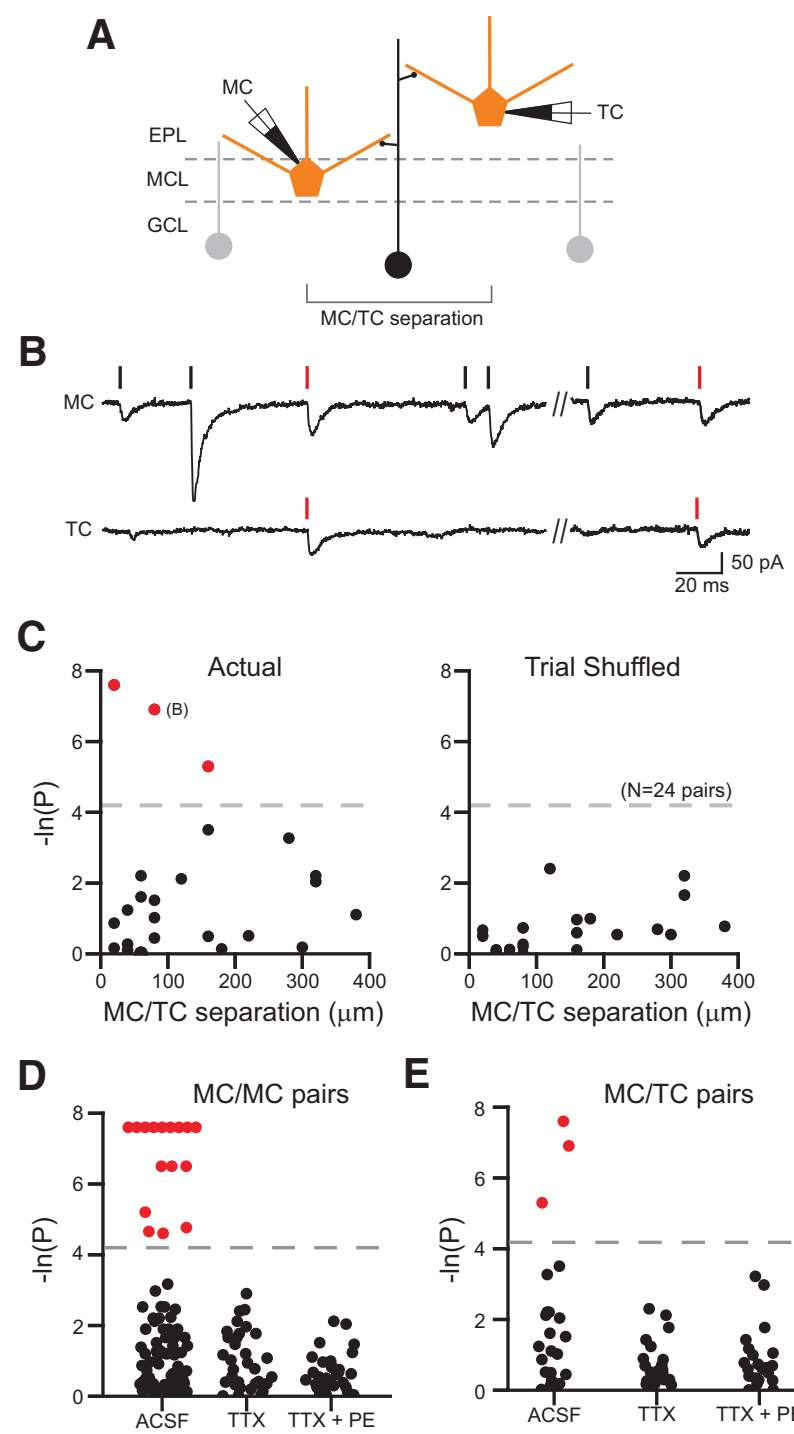

E

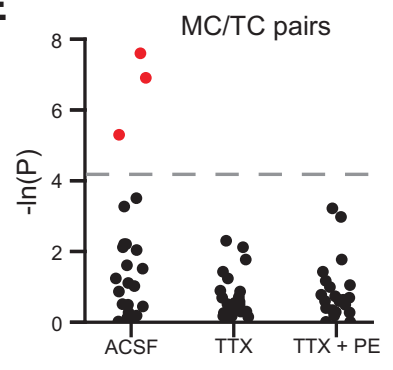

Figure 5. Coincident inhibition in mitral/TC paired recordings. $A$, Diagram of recording configuration. $B$, Simultaneous MC (top) and TC (bottom) recording showing near-coincident IPSCS (onset lags: -0.1 and $-0.9 \mathrm{~ms}$ ). C, Plot of the relationship between the degree of inhibitory synchrony and somatic separation in $24 \mathrm{MC} / \mathrm{TC}$ paired recordings based on the actual (left) and trial shuffled (right) IPSC onset times. Three experiments with statistically significant inhibitory synchrony ( $p<0.015$; dashed lines) are denoted by red symbols. The $x$-axis reflects only the component of the somatic separation along the MCL. $D$, Plot of the degree of inhibitory synchrony in MC/MC paired recordings assayed in ACSF $(N=89)$, TTX $(N=43)$, and TTX + PE $(N=43)$. Experiments with statistically significant inhibitory synchrony $(p<0.015$; dashed line) are denoted by red symbols. $E$, Similar plot for MC/TC paired recordings ( $N=24$ experiments in ACSF, $N=22$ in TTX and TTX + PE).

tistically significant decrease in mean IPSC amplitude $(29 \%$ decrease; Fig. 6E). This difference primarily reflected an overrepresentation of IPSCs with very small amplitudes (see IPSC amplitude histograms in Fig. 6F, inset). Therefore, we tested whether the lack of statistically significant inhibitory synchrony following treatment with PE and high-K ACSF reflected a "dilution" effect that prevented detecting above-chance inhibitory synchrony. We tested for this possibility by restricting our cross-correlation analysis to spontaneous IPSCs greater than an arbitrary minimum amplitude. As shown in the plot in Figure $6 F$, we failed to find statistically significant inhibitory synchrony when analyzing different subsets of large-amplitude IPSCs in the $10 \mathrm{MC}$ pairs with no evident inhibitory synchrony in high-K ACSF. Eliminat- ing spontaneous IPSCs $<50$ pA also abolished inhibitory synchrony in the one $\mathrm{MC} / \mathrm{MC}$ paired recording with statistically significant rates of near-coincident IPSCs (Fig. 6G), suggesting that some synchronous inhibitory inputs generated relatively smallamplitude $(<50 \mathrm{pA})$ IPSCs.

Passively depolarizing bulbar neurons with high-K ACSF also increased the spatial extent of inhibitory synchrony. As shown in Figure 7A, MC pairs with intersoma distances up to $300 \mu \mathrm{m}$ exhibited statistically significant inhibitory synchrony (versus up to $220 \mu \mathrm{m}$ in control ACSF). As in previous control analyses, trial shuffling eliminated all statistically significant inhibitory synchrony (Fig. 7A, right). The overall proportion of MC/MC paired recordings with significant inhibitory synchrony increased from $18 \%$ in control ACSF to $47 \%$ in high-K ACSF (Fig. $7 B$ ). We found an even more pronounced increase in the proportion of experiments with significant inhibitory synchrony when only considering MC pairs with intersoma separations $>100 \mu \mathrm{m}$ (Fig. $7 B$, right bars). Consistent with this hypothesis, we found a statistically significant difference between plots of cumulative intersoma distance in experiments with inhibitory synchrony in control and high-K ACSF (Fig. 7C, left). The midpoint in MC separations with inhibitory synchrony (similar to $\mathrm{EC}_{50}$ estimates) shifted from $60 \mu \mathrm{m}$ in control to $140 \mu \mathrm{m}$ in high-K ACSF (arrowheads along the $x$-axis in Fig. $7 C$, left). The somatic separation where we found a $50 \%$ probability of detecting above-chance coincident IPSCs in control ACSF $(60 \mu \mathrm{m})$ was similar to the mean somatic separation in the $16 \mathrm{MC} / \mathrm{MC}$ pairs coincident inhibition described above $(80 \mu \mathrm{m})$. There was no difference in the cumulative intersoma distance plots when considering all MC/MC pairs (regardless of whether they had inhibitory synchrony) between control and high-K ACSF ( $p=0.71$; Kolmogorov-Smirnov test; Fig. $7 C$, right).

Although high-K ACSF increased the fraction of experiments with inhibitory synchrony and the spatial extent of inhibitory synchrony, this treatment did not affect the proportion of putative synchronized IPSCs within each recording. Actual measurements of near-coincident IPSCs (e.g., number of IPSCs in one recording with a corresponding IPSC within $3 \mathrm{~ms}$ in the other, simultaneous recording) reflect the sum of two different frequencies: the rate of real ("biological") coincident IPSCs, presumably corresponding to coordinated release of GABA at two different synapses from the same interneuron, and the rate of chance coincidences. We calculated the "excess coincidence rate" reflecting an estimate of the underlying frequency of actual coordinated GABA release events by subtracting the rate of random coincidences (computed by permuting inter-IPSC intervals) from the measured rate of near-coincident IPSCs. The excess inhibitory coincidence rate modestly increased from $0.70 \pm 0.14 \mathrm{~Hz}$ in the $16 \mathrm{MC} / \mathrm{MC}$ with statistically significant inhibitory synchrony in control ACSF to $1.62 \pm 0.69 \mathrm{~Hz}$ in the $9 \mathrm{MC} / \mathrm{MC}$ pairs with inhibitory synchrony recorded in high-K ACSF ( $p=0.12$; unpaired $t$ test). However, expressed as a proportion of the ongoing spontaneous IPSC frequency in each condition, there was almost no difference in the rate of excess IPSCs between control ( $8.4 \%$ of all spontaneous IPSCs) and high-K ACSF (7.5\%; Fig. 7D). As expected, we found near-zero rates of excess coincident IPSCs after trial shuffling or when assaying MC/MC pairs that did not have statistically significant inhibitory synchrony (Fig. 7D, right columns).

The similar percentage of near-coincident events detected under different levels of rates of ongoing spontaneous IPSCs suggests that inhibitory synchrony reflected inputs from small but constant fraction of presynaptic inputs. This $8 \%$ estimate could 
A

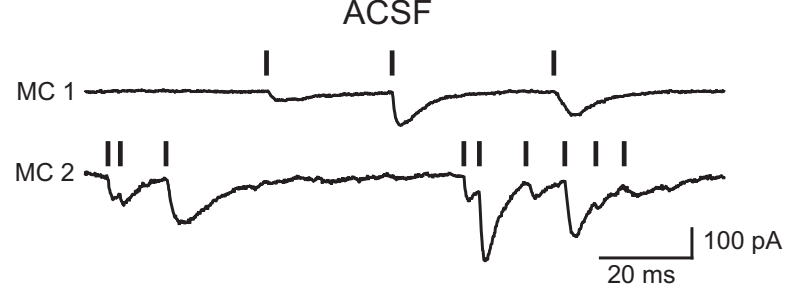

High K

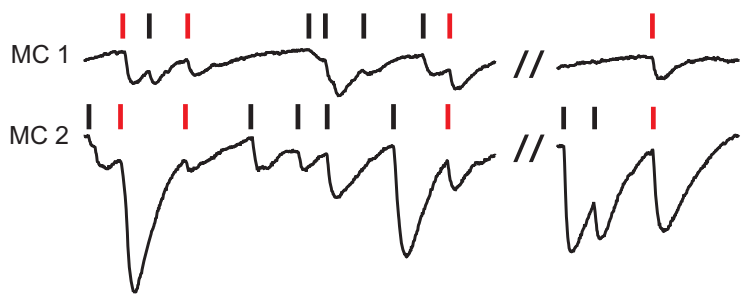

B

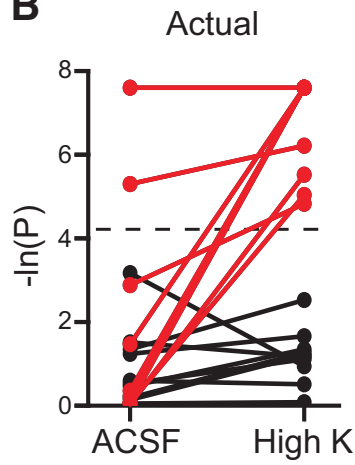

Trial Shuffle

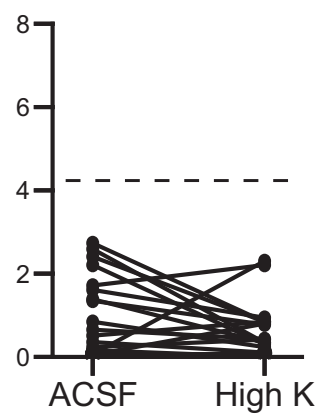

C

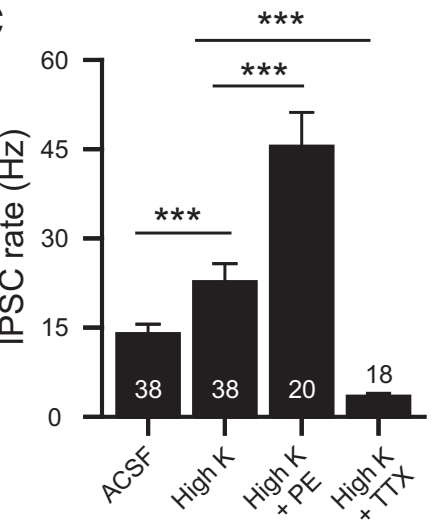

D

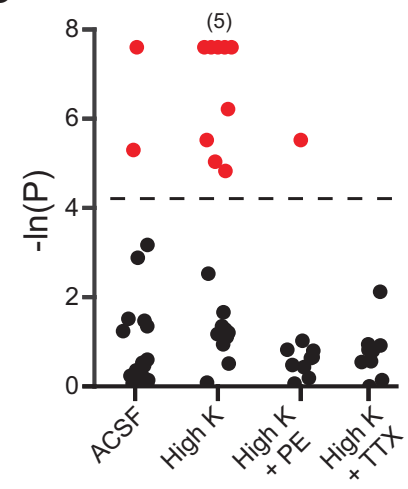

E

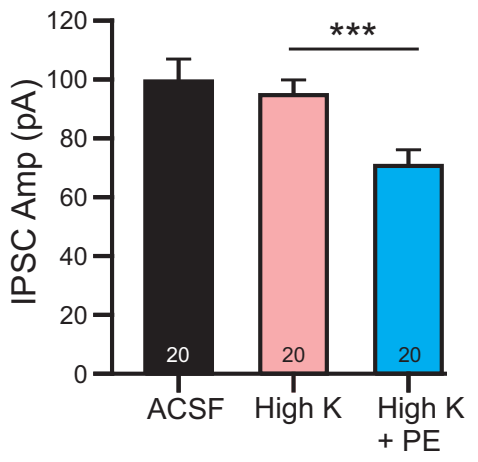

F

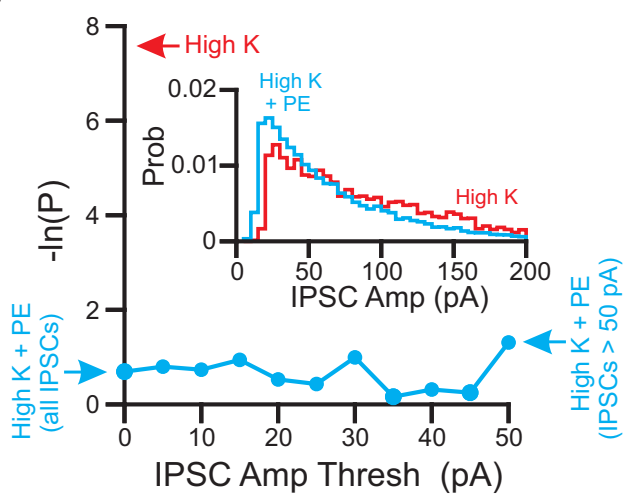

G

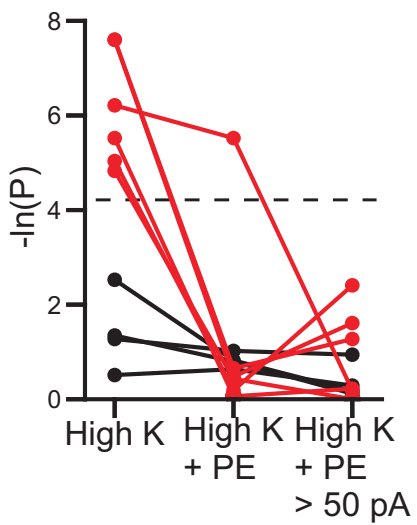

Figure 6. Passive depolarization with elevated $\mathrm{K}^{+}$increases inhibitory synchrony. $\boldsymbol{A}$, Example dual MC recording with near-coincident IPSCs (onset lags: $-0.4,-0.4,-0.3$, and 0.1 ms) in high-K ACSF but not in control ACSF. B, Plot of degree of inhibitory synchrony in 19 paired MC recordings tested in control and high-K ACSF. $p$-values based on actual IPSC onset times are shown on the left and those after trial shuffling on the right. Experiments with statistically significant inhibitory synchrony in high-K ACSF are indicated by red lines (7 experiments with $p<0.015$ only in high-KACSF and 2 experiments with $p<0.015$ in both conditions). C, Plot of mean IPSC rate after passive depolarization using high-KACSF. ${ }^{* *} A C S F v$ s high-K ACSF: $p=0.0001, t_{(37)}=4.35$, paired $t$ test; high-K vs high-K + PE: $p=0.00044, t_{(56)}=3.74$; unpaired $t$ test; high-K to high-K + TTX: $p=0.00011, t_{(54)}=4.17$, unpaired $t$ test. $D$, Plot of the degree of inhibitory synchrony in MC/MC paired recordings after passive depolarization with high-K ACSF. Dashed line represents same $p=0.015$ threshold for statistical significance used throughout study. Cluster of 5 experiments with similar $p$-values indicated by "(5)." $\boldsymbol{E}$, Plot of mean IPSC amplitude after passive depolarization. ${ }^{* * *} p=0.0035\left(t_{(19)}=3.11\right.$, paired $t$ test) $\boldsymbol{F}$, Plot of degree of inhibitory synchrony versus the lower cutoff of IPSC amplitudes analyzed in one MC/MC paired recording in high-K + PE. Far right point represents results of cross-correlation analysis including only IPSCs $>50 \mathrm{pA}$ in both MCs; far left point reflects the cross-correlation analysis when including all detected IPSCs. This paired recording showed statistically significant inhibitory synchrony in high-K ACSF (red arrow by top of $y$-axis) Inset, Histogram of IPSC amplitudes in this example paired recording in high-K (red; $N=5419$ IPSCs) and high-K + PE (blue; $N=18588$ IPSCs) conditions. G, Plot of the degree of inhibitory coincidence after passive depolarization with high-K ACSF. Middle, Eperiments in high-K + PE when all IPSCs are included. Right, High-K + PE when only IPSCs $>50 \mathrm{pA}$ are included. Dashed line indicates $p=0.015$.

arise from a single spontaneously active interneuron that innervated both MCs assuming each MC also receives input from $\sim 12$ other active interneurons (or from two convergent interneurons and $\sim 23$ other active interneurons, etc.). This percentage would remain constant during passive depolarization tests if the treatment had a similar effect in all presynaptic GCs. If the inhibitory coincidence that we report arises on average from a single active interneuron, then this provides an estimate of the total number of active presynaptic interneurons each $\mathrm{MC}$ receives $(\sim 13)$.

Urban and colleagues (Galán et al., 2006) have studied the functional effect of coincident inhibition onto pairs of OB prin- cipal cells by injecting fixed patterns of randomly timed $\alpha$ functions (mimicking GABAergic IPSCs) with defined percentages of coincident inputs applied to both cells. They found that even relatively low percentages of coincident hyperpolarizing inputs (20\%, similar to the $\sim 8 \%$ we observe) were effective in generating synchronized MC spikes (see Fig. $4 A$ in Galán et al., 2006). Presumably, the brief hyperpolarizing current injections used in that study evoked synchronized rebound spiking in both MCs (Balu and Strowbridge, 2007, Balu et al., 2007; Schoppa, 2006), although the specific biophysical mechanisms involved were not defined. Together with the present results, this work suggests that 
A

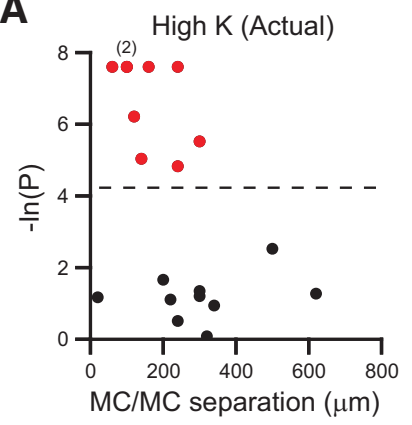

High K (Trial Shuffle)

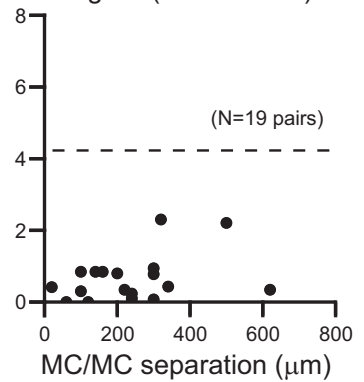

B

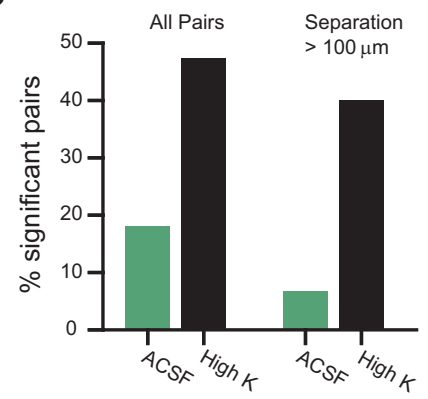

C

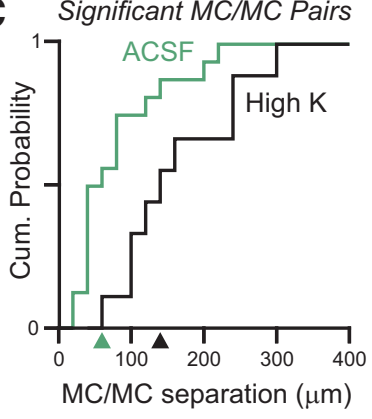

All MC/MC Pairs

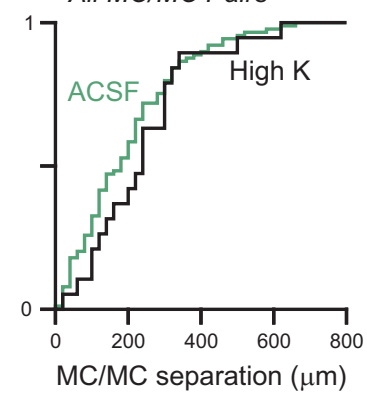

D

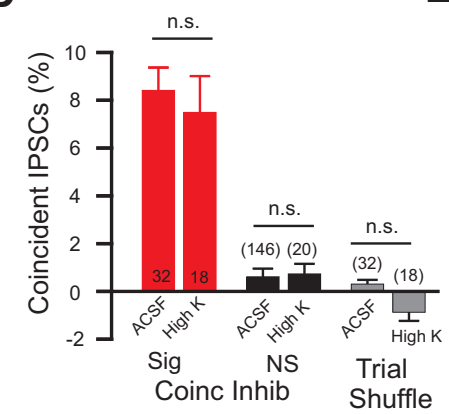

E

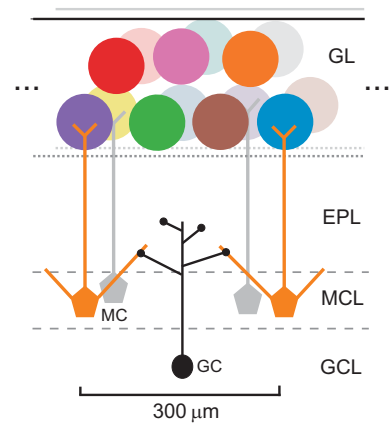

Figure 7. Passive depolarization expands spatial scale of coincident inhibition. $A$, Plot of the relationship between degree of inhibitory coincidence and somatic separation in $19 \mathrm{MC} / \mathrm{MC}$ paired recordings based on actual (left) and trial-shuffled (right) IPSC onset times. Two experiments with similar $p$-values indicated by "(2)" in left plot. Dashed line at $p=0.015$. B, Comparison of the fraction of MC/MC paired recording experiments with statistically significant inhibitory synchrony $(p<0.015)$ in control (green bars) and high-K ACSF (black). Left bars represent all MC/MC paired recording experiments. Right bars represent only experiments in which MC cell bodies were separated by $>100 \mu \mathrm{m}$. C, Plot of cumulative distribution of MC somatic separations in control (green) and high-K ACSF (black). Plots on left are restricted to MC/MC paired recordings with statistically significant inhibitory synchrony ( $N=16$ ACSF and 9 high-K; curves different, $p=0.0486$, $D_{(19,19)}=0.421$, Kolmogorov-Smirnov test). Plot on right reflects all MC/MC experiments ( $N=89$ ACSF and 19 high-K). Arrowheads by $x$-axis in the left plot indicate MC somatic separation cutoffs that include half of the relevant population (analogous to $\mathrm{EC}_{50}$ estimates). D, Plot of percentage of all IPSCs that reflect "excess" coincident IPSCs (beyond the fraction of near-coincident IPSCs (onset lag $<3 \mathrm{~ms}$ ) expected by chance) in experiments with statistically significant inhibitory synchrony (red bars), experiments without demonstrable inhibitory synchrony (black bars), and in all MC/MC paired recordings after trial shuffling (gray bars). All comparisons between bar pairs did not differ significantly (all $p>0.05$, unpaired $t$ test). $E$, Diagram of expected fan-out from individual bulbar interneurons (example GC illustrated). See Discussion for details.

even the relatively low frequency of coincident inhibition generated by spontaneously active presynaptic interneurons can generate a functionally significant signature in the spike output of the $\mathrm{OB}$ (transiently synchronized MC spikes).

\section{Discussion}

In this study, we assayed OB synaptic connectivity patterns using paired recordings and make three primary conclusions. First, we find that the frequency of spontaneous IPSCs is strongly correlated with the frequency of TTX-resistant IPSC in MCs, suggesting that most inhibitory inputs to MCs behave as a uniform population. Second, we find that $\mathrm{Na}^{+}$-spike-driven coincident inhibition can link pairs of principal cells belonging to different glomerular columns as well as different types of principal cells (MCs and TCs). These results provide the first direct demonstration that distant pairs of principal cells can be functionally linked by coincident inhibition under physiological conditions. This finding is consistent with previous results from Schoppa (2006), who observed inhibitory coupling between distant MCs after tetanic electrical stimulation with near-coincident IPSCs evident in $\sim 40 \%$ of nearby MCs based on the presence of a central peak in cross-correlation plots. However, direct pathway stimulation can trigger synchronized firing in multiple interneurons, potentially generating coincident inhibitory postsynaptic responses in MCs. These types of "common driver" mechanisms are unlikely to account for inhibitory synchrony apparent under resting (nonstimulated) conditions used in the present study, leaving sponta- neous $\mathrm{Na}^{+}$spiking in GCs that are presynaptic to both MCs as the most likely explanation for above-chance rates of coincident IPSC. Finally, we found that coincident inhibition onto MCs depends on $\mathrm{Na}^{+}$spiking in GCs and can be disrupted by strong depolarizing stimuli. Together, these results suggest that bulbar interneurons can play an important role in the olfactory system by coordinating responses in principal cells belonging to different glomerular channels. These synaptic interactions can function to modulate MC and TC firing patterns to reflect contextual information associated with the larger glomerular network activated by an odor.

\section{Difference in inhibitory tone between MCs and TCs}

To our knowledge, our study is the first to compare inhibitory tone in MCs and TCs under normal physiological conditions and when $\mathrm{Na}^{+}$-based spiking is abolished by TTX. Our finding that TCs receive less pronounced inhibition (approximately threefold fewer IPSCs) is consistent with several previous reports that assayed the rate of spontaneous inhibitory postsynaptic responses (Geramita et al., 2016; Ezeh et al., 1993). This different in spontaneous IPSC/P rate could be explained by preferential innervation of MCs by more active interneurons compared with TCs or by a difference in overall density of inhibitory innervation in the principal cell types. Our observation that the threefold difference in IPSC rate between MCs and TCs is maintained when $\mathrm{Na}^{+}$ spiking is blocked with TTX and then when GC excitability is enhanced by PE suggests that this difference reflects primarily a 
higher density of inhibitory synaptic inputs on MCs. Because our ability to detect spontaneous IPSCs is likely limited to the synapses within 100-150 $\mu \mathrm{m}$ of the somata (Lowe, 2002) differences in the length of the secondary dendrites between MCs and TCs are unlikely to influence the incidence of coincident inhibition detected.

Secondary dendrites of MCs and TCs also arborize in different zones within the EPL, where they contact different subpopulations of GCs (Orona et al., 1983; Mori et al., 1983). Our finding that coincident inhibition can be detected in MC/TC pairs suggests that the distinction between MC- and TC-targeting GCs is not absolute. Diminished inhibitory tone in TCs may reflect a lower density of reciprocal contacts on TC-targeting GCs. Although Greer and colleagues (Bartel et al., 2015) found a similar density of reciprocal synapses throughout the EPL, to our knowledge, the density of dendrodendritic synapses formed by different subclasses of GCs has not be been defined. Urban and colleagues (Geramita et al., 2016) found that TCs were more excitable than MCs after glomerular stimulation, suggesting that any reduction in TC-to-GC synaptic density may be compensated for by strong excitatory inputs to TCs.

\section{Synchronized inhibition links principal cells across multiple glomerular columns}

We detected synchronized inhibition using standard methods (Narayanan and Laubach, 2009) based on cross-correlation analysis of IPSC onset times and used two different control procedures to estimate the frequency of coincident IPSCs expected by chance in each experiment (interval permutation and trial shuffling). The spontaneous IPSC frequency was only modestly reduced in visualized MCs with apical dendrites truncated before reaching the GL compared with intact MCs, suggesting that most of the inhibitory tone detected in somatic recordings from $\mathrm{OB}$ principal cells originates from interneurons outside of the GL, presumably GCs. Although several populations of non-GC interneurons exist in the GCL, these appear to target either TCs (Burton and Urban, 2015) or GCs (Pressler and Strowbridge, 2006; Burton et al., 2017). A recent study (Kato et al., 2013) has found that parvalbumin (PV)-positive interneurons located in the EPL form reciprocal synapses with MCs and therefore could also contribute to the inhibitory synchrony that we observed. However, PV EPL interneurons appear to fire at high rates $(>40$ $\mathrm{Hz}$ in Kato et al., 2013), which is inconsistent with the very low rates of beyond-chance synchronized IPSCs in our MC/MC paired recordings $(\sim 0.7 \mathrm{~Hz}$ in ACSF).

Coincident inhibition onto $\mathrm{MC} / \mathrm{MC}$ and $\mathrm{MC} / \mathrm{TC}$ pairs was abolished in TTX, suggesting that they likely originate from GABA release sites coupled by $\mathrm{Na}^{+}$-based action potentials in GCs. The absence of detectable inhibitory synchrony in our study was unlikely to occur simply because of the lower IPSC rate in TTX because we also observed no detectable coincident inhibition (beyond chance levels) when GCs were stimulated with PE after $\mathrm{Na}^{+}$spikes were abolished. This treatment restored nearcontrol rates of spontaneous IPSCs in both MCs and TCs but did not reveal inhibitory synchrony. This finding suggests that, in the absence of $\mathrm{Na}^{+}$-based APs, direct depolarization of GCs does not trigger coordinated GABA release at multiple dendritic spines that we can detect using paired recordings.

Granule cells generate APs in response to depolarizing stimuli that propagate throughout the dendritic arbor (Egger et al., 2003). Because many of the MC pairs that we found that receive synchronized inhibition were separated by distances that are the far extreme of what should be possible given the electrotonic length constant of MC secondary dendrites assayed from focal GABA uncaging ( $75 \mu \mathrm{m}$; Lowe, 2002$)$, it is likely that $\mathrm{Na}^{+}{ }_{-}$ based APs coupled GABA release at different spines within the GC dendritic tree. This mechanism would explain the ability of TTX to abolish inhibitory coupling in MC/MC and MC/TC paired recordings and the inability of increasing excitability in TTX with PE to recover inhibitory synchrony in pairs known to share a common presynaptic interneuron.

Functional (Wienisch and Murthy, 2016) and computational (Brea et al., 2009) studies have suggested an important role for spatially localized $\mathrm{Na}^{+}$and $\mathrm{Ca}^{2+}$ spikes in GCs (Egger et al., 2005; Zelles et al., 2006; Bywalez et al., 2015). The extent of spike propagation within GC dendrites represents an attractive mechanism to regulate the degree of inhibitory synchrony in principal cells. At the smallest extreme, individual GC spines are likely able to release GABA autonomously, leading to an increase in asynchronously inhibition in MCs. Removing extracellular $\mathrm{Mg}^{2+}$ greatly facilitates GABA release from GCs by enhancing $\mathrm{Ca}^{2+}$ influx through NMDA receptors located in dendritic spines (Isaacson and Strowbridge, 1998; Schmidt and Strowbridge, 2014). However, this treatment does not lead to an increase in coincident IPSPs, even between nearby pairs of MCs (Schmidt and Strowbridge, 2014), likely reflecting uncoordinated release events at different spines. In contrast to low- $\mathrm{Mg}^{2+}$ treatment, the present study found that increasing extracellular $\mathrm{K}^{+}$increased both IPSC frequency and the incidence of coincident inhibition. Presumably, elevated $\mathrm{K}^{+}$increased the frequency of spontaneous spiking in GCs and therefore the frequency of near-simultaneous release of GABA on spines that synapse onto different principal cells. Further increasing the excitability of GCs by combining elevated $\mathrm{K}^{+}$with PE greatly diminished the incidence of synchronized inhibition. This effect probably reflected depolarization blockade of AP generation in GCs rather than dilution of synchronized IPSCs by an elevated frequency of small-amplitude asynchronous events because restricting our analysis to large-amplitude IPSCs failed to recover evidence for coincident inhibition.

\section{Functional significance of coincident inhibition onto $\mathrm{OB}$ principal cells}

The central finding in this study is that individual GCs can generate coordinated inhibition onto relatively distant principal cells. This result suggests that GCs can function to influence firing patterns of output neurons belonging to different glomerular columns. Although we demonstrate directly that coincidence inhibition occurs in MCs associated with nearby glomeruli (Fig. 4), the spatial extent over which we observed synchronized inhibition suggests that individual GCs influence activity over multiple glomerular columns. The average diameter of a glomerulus is $\sim 75 \mu \mathrm{m}$ (range 50-120 $\mu \mathrm{m}$; Pinching and Powell, 1971) and a rough estimate of the $2 \mathrm{D}$ packing density is 2.5 glomeruli per 100 $\mu \mathrm{m}$ span parallel to the MCL (185 $\mu \mathrm{m}$ estimated GL width). Assuming at least two layers of intact glomeruli per slice (but likely three or four in some slices), leads to a maximal span of 14 glomerular columns per GC (Fig. 7E) and an estimated average connectivity of seven columns per GC. This analysis is based solely on detecting the incidence of coincident IPSCs exceeding chance, so it likely represents an underestimate because infrequently discharging GCs will generate too few coincident IPSCs to be detected in our assay. This analysis also does not account for the variable trajectory of the apical dendrite as it passed through the EPL, which also could enhance the effective glomerular span of GC-mediated inhibition. 
Because there is very little chemotopic structure within the GL (Soucy et al., 2009; Fantana et al., 2008; Luo and Katz, 2001; Ma et al., 2012), it is possible for an individual GC to affect the firing patterns of principal cells responding to a wide range of odorants. Inhibitory postsynaptic responses can trigger rebound spikes in MCs (Balu and Strowbridge, 2007, Balu et al., 2007; Desmaisons et al., 1999; Schoppa, 2006), including synchronized APs in pairs of MCs in response to coincident inhibition (Galán et al., 2006). Through synchronous IPSP-triggered rebound spikes, the functional impact of coincident inhibition onto subsets of principal cells is likely magnified and transmitted to downstream cortical regions that detect transiently synchronized MC inputs (Salinas and Sejnowski, 2000). In addition to triggering synchronized firing, coordinated inhibition also may function to sculpt MC discharges to enhance subtle differences evoked by sensory input, facilitating the decorrelation of related odor responses (Friedrich and Laurent, 2001; Cazakoff et al., 2014; Shepherd et al., 2007; Friedrich and Wiechert, 2014; Gschwend et al., 2015). Because most MC/GC and TC/GC synaptic connections in the EPL are reciprocal (Isaacson and Strowbridge, 1998; Rall et al., 1966), our results suggest that individual GCs also receive excitatory input from a relatively large range of sensory neuron subtypes, helping to explain the complex sensory responses observed in GC recordings in vivo (Kato et al., 2012; Fukunaga et al., 2014; Cazakoff et al., 2014; Cang and Isaacson, 2003; Tan et al., 2010; Luo and Katz, 2001; Wellis and Scott, 1990).

\section{References}

Abraham NM, Egger V, Shimshek DR, Renden R, Fukunaga I, Sprengel R, Seeburg PH, Klugmann M, Margrie TW, Schaefer AT, Kuner T (2010) Synaptic inhibition in the olfactory bulb accelerates odor discrimination in mice. Neuron 65:399-411. CrossRef Medline

Araneda RC, Firestein S (2006) Adrenergic enhancement of inhibitory transmission in the accessory olfactory bulb. J Neurosci 26:3292-3298. CrossRef Medline

Arevian AC, Kapoor V, Urban NN (2008) Activity-dependent gating of lateral inhibition in the mouse olfactory bulb. Nat Neurosci 11:80-87. CrossRef Medline

Balu R, Strowbridge BW (2007) Opposing inward and outward conductances regulate rebound discharges in olfactory mitral cells. J Neurophysiol 97:1959-1968. CrossRef Medline

Balu R, Pressler RT, Strowbridge BW (2007) Multiple modes of synaptic excitation of olfactory bulb granule cells. J Neurosci 27:5621-5632. CrossRef Medline

Bartel DL, Rela L, Hsieh L, Greer CA (2015) Dendrodendritic synapses in the mouse olfactory bulb external plexiform layer. J Comp Neurol 523: 1145-1161. CrossRef Medline

Brea JN, Kay LM, Kopell NJ (2009) Biophysical model for gamma rhythms in the olfactory bulb via subthreshold oscillations. Proc Natl Acad Sci U S A 106:21954-21959. CrossRef Medline

Burton SD, Urban NN (2015) Rapid feedforward inhibition and asynchronous excitation regulate granule cell activity in the mammalian main olfactory bulb. J Neurosci 35:14103-14122. CrossRef Medline

Burton SD, LaRocca G, Liu A, Cheetham CE, Urban NN (2017) Olfactory bulb deep short-axon cells mediate widespread inhibition of tufted cell apical dendrites. J Neurosci 37:1117-1138. Medline

Bywalez WG, Patirniche D, Rupprecht V, Stemmler M, Herz AV, Pálfi D, Rózsa B, Egger V (2015) Local postsynaptic voltage-gated sodium channel activation in dendritic spines of olfactory bulb granule cells. Neuron 85:590-601. CrossRef Medline

Cang J, Isaacson JS (2003) In vivo whole-cell recording of odor-evoked synaptic transmission in the rat olfactory bulb. J Neurosci 23:4108-4116. Medline

Carey RM, Sherwood WE, Shipley MT, Borisyuk A, Wachowiak M (2015) Role of intraglomerular circuits in shaping temporally structured responses to naturalistic inhalation-driven sensory input to the olfactory bulb. J Neurophysiol 113:3112-3129. CrossRef Medline

Cazakoff BN, Lau BY, Crump KL, Demmer HS, Shea SD (2014) Broadly tuned and respiration-independent inhibition in the olfactory bulb of awake mice. Nat Neurosci 17:569-576. CrossRef Medline

Davis BJ, Macrides F (1981) The organization of centrifugal projections from the anterior olfactory nucleus, ventral hippocampal rudiment, and piriform cortex to the main olfactory bulb in the hamster: an autoradiographic study. J Comp Neurol 203:475-493. CrossRef Medline

Desmaisons D, Vincent JD, Lledo PM (1999) Control of action potential timing by intrinsic subthreshold oscillations in olfactory bulb output neurons. J Neurosci 19:10727-10737. Medline

Dhawale AK, Hagiwara A, Bhalla US, Murthy VN, Albeanu DF (2010) Nonredundant odor coding by sister mitral cells revealed by light addressable glomeruli in the mouse. Nat Neurosci 13:1404-1412. CrossRef Medline

Egger V, Svoboda K, Mainen ZF (2003) Mechanisms of lateral inhibition in the olfactory bulb: efficiency and modulation of spike-evoked calcium influx into granule cells. J Neurosci 23:7551-7558. Medline

Egger V, Svoboda K, Mainen ZF (2005) Dendrodendritic synaptic signals in olfactory bulb granule cells: local spine boost and global low-threshold spike. J Neurosci 25:3521-3530. CrossRef Medline

Ezeh PI, Wellis DP, Scott JW (1993) Organization of inhibition in the rat olfactory bulb external plexiform layer. J Neurophysiol 70:263-274. Medline

Fantana AL, Soucy ER, Meister M (2008) Rat olfactory bulb mitral cells receive sparse glomerular inputs. Neuron 59:802-814. CrossRef Medline

Friedrich RW, Laurent G (2001) Dynamic optimization of odor representations by slow temporal patterning of mitral cell activity. Science 291:889894. CrossRef Medline

Friedrich RW, Wiechert MT (2014) Neuronal circuits and computations: pattern decorrelation in the olfactory bulb. FEBS Lett 588:2504-2513. CrossRef Medline

Fukunaga I, Herb JT, Kollo M, Boyden ES, Schaefer AT (2014) Independent control of gamma and theta activity by distinct interneuron networks in the olfactory bulb. Nat Neurosci 17:1208-1216. CrossRef Medline

Galán RF, Fourcaud-Trocmé N, Ermentrout GB, Urban NN (2006) Correlation-induced synchronization of oscillations in olfactory bulb neurons. J Neurosci 26:3646-3655. CrossRef Medline

Gao Y, Strowbridge BW (2009) Long-term plasticity of excitatory inputs to granule cells in the rat olfactory bulb. Nat Neurosci 12:731-733. CrossRef Medline

Gelman A, Hill J, Yajima M (2012) Why we (usually) don't have to worry about multiple comparisons. Journal of Research on Educational Effectiveness 5:189-211. CrossRef

Geramita MA, Burton SD, Urban NN (2016) Distinct lateral inhibitory circuits drive parallel processing of sensory information in the mammalian olfactory bulb. Elife 5: pii: e16039. CrossRef Medline

Gschwend O, Abraham NM, Lagier S, Begnaud F, Rodriguez I, Carleton A (2015) Neuronal pattern separation in the olfactory bulb improves odor discrimination learning. Nat Neurosci 18:1474-1482. CrossRef Medline

Hahnloser RH (2007) Cross-intensity functions and the estimate of spiketime jitter. Biol Cybern 96:497-506. CrossRef Medline

Hyde RA, Strowbridge BW (2012) Mnemonic representations of transient stimuli and temporal sequences in the rodent hippocampus in vitro. Nat Neurosci 15:1430-1438. CrossRef Medline

Isaacson JS, Strowbridge BW (1998) Olfactory reciprocal synapses: dendritic signaling in the CNS. Neuron 20:749-761. CrossRef Medline

Kato HK, Chu MW, Isaacson JS, Komiyama T (2012) Dynamic sensory representations in the olfactory bulb: modulation by wakefulness and experience. Neuron 76:962-975. CrossRef Medline

Kato HK, Gillet SN, Peters AJ, Isaacson JS, Komiyama T (2013) Parvalbuminexpressing interneurons linearly control olfactory bulb output. Neuron 80 : 1218-1231. CrossRef Medline

Ke MT, Fujimoto S, Imai T (2013) SeeDB: A simple and morphologypreserving optical clearing agent for neuronal circuit reconstruction. Nat Neurosci 16:1154-1161. CrossRef Medline

Korogod N, Petersen CC, Knott GW (2015) Ultrastructural analysis of adult mouse neocortex comparing aldehyde perfusion with cryo fixation. Elife 4. CrossRef Medline

Lagier S, Carleton A, Lledo PM (2004) Interplay between local gabaergic interneurons and relay neurons generates gamma oscillations in the rat olfactory bulb. J Neurosci 24:4382-4392. CrossRef Medline

Larimer P, Strowbridge BW (2008) Nonrandom local circuits in the dentate gyrus. J Neurosci 28:12212-12223. CrossRef Medline

Larimer P, Strowbridge BW (2010) Representing information in cell assem- 
blies: persistent activity mediated by semilunar granule cells. Nat Neurosci 13:213-222. CrossRef Medline

Lowe G (2002) Inhibition of backpropagating action potentials in mitral cell secondary dendrites. J Neurophysiol 88:64-85. Medline

Luo M, Katz LC (2001) Response correlation maps of neurons in the mammalian olfactory bulb. Neuron 32:1165-1179. CrossRef Medline

Luskin MB, Price JL (1983) The topographic organization of associational fibers of the olfactory system in the rat, including centrifugal fibers to the olfactory bulb. J Comp Neurol 216:264-291. CrossRef Medline

Ma L, Qiu Q, Gradwohl S, Scott A, Yu EQ, Alexander R, Wiegraebe W, Yu CR (2012) Distributed representation of chemical features and tunotopic organization of glomeruli in the mouse olfactory bulb. Proc Natl Acad Sci U S A 109:5481-5486. CrossRef Medline

McIntyre AB, Cleland TA (2016) Biophysical constraints on lateral inhibition in the olfactory bulb. J Neurophysiol 115:2937-2949. CrossRef Medline

McLennan H (1971) The pharmacology of inhibition of mitral cells in the olfactory bulb. Brain Res 29:177-184. CrossRef Medline

Mori K, Kishi K, Ojima H (1983) Distribution of dendrites of mitral, displaced mitral, tufted, and granule cells in the rabbit olfactory bulb. J Comp Neurol 219:339-355. CrossRef Medline

Narayanan NS, Laubach M (2009) Methods for studying functional interactions among neuronal populations. Methods Mol Biol 489:135-165. CrossRef Medline

Nissant A, Bardy C, Katagiri H, Murray K, Lledo PM (2009) Adult neurogenesis promotes synaptic plasticity in the olfactory bulb. Nat Neurosci 12:728-730. CrossRef Medline

Orona E, Scott JW, Rainer EC (1983) Different granule cell populations innervate superficial and deep regions of the external plexiform layer in rat olfactory bulb. J Comp Neurol 217:227-237. CrossRef Medline

Orona E, Rainer EC, Scott JW (1984) Dendritic and axonal organization of mitral and tufted cells in the rat olfactory bulb. J Comp Neurol 226:346356. CrossRef Medline

Petreanu L, Alvarez-Buylla A (2002) Maturation and death of adult-born olfactory bulb granule neurons: role of olfaction. J Neurosci 22:61066113. Medline

Pinching AJ, Powell TP (1971) The neuropil of the glomeruli of the olfactory bulb. J Cell Sci 9:347-377. Medline

Pressler RT, Strowbridge BW (2006) Blanes cells mediate persistent feedforward inhibition onto granule cells in the olfactory bulb. Neuron 49:889904. CrossRef Medline

Pressler RT, Rozman PA, Strowbridge BW (2013) Voltage-dependent intrinsic bursting in olfactory bulb Golgi cells. Learn Mem 20:459-466. CrossRef Medline

Price JL, Powell TP (1970) The morphology of the granule cells of the olfactory bulb. J Cell Sci 7:91-123. Medline

Rall W, Shepherd GM, Reese TS, Brightman MW (1966) Dendrodendritic synaptic pathway for inhibition in the olfactory bulb. Exp Neurol 14:4456. CrossRef Medline

Salinas E, Sejnowski TJ (2000) Impact of correlated synaptic input on out- put firing rate and variability in simple neuronal models. J Neurosci 20: 6193-6209. Medline

Salmoiraghi GC, Bloom FE, Costa E (1964) Adrenergic mechanisms in rabbit olfactory bulb. Am J Physiol 207:1417-1424. Medline

Schmidt LJ, Strowbridge BW (2014) Modulation of olfactory bulb network activity by serotonin: synchronous inhibition of mitral cells mediated by spatially localized GABAergic microcircuits. Learn Mem 21:406-416. CrossRef Medline

Schoppa NE (2006) Synchronization of olfactory bulb mitral cells by precisely timed inhibitory inputs. Neuron 49:271-283. CrossRef Medline

Sham PC, Purcell SM (2014) Statistical power and significance testing in large-scale genetic studies. Nat Rev Genet 15:335-346. CrossRef Medline

Shepherd GM, Chen WR, Willhite D, Migliore M, Greer CA (2007) The olfactory granule cell: from classical enigma to central role in olfactory processing. Brain Res Rev 55:373-382. CrossRef Medline

Soucy ER, Albeanu DF, Fantana AL, Murthy VN, Meister M (2009) Precision and diversity in an odor map on the olfactory bulb. Nat Neurosci 12:210-220. CrossRef Medline

Stopfer M, Bhagavan S, Smith BH, Laurent G (1997) Impaired odour discrimination on desynchronization of odour-encoding neural assemblies. Nature 390:70-74. CrossRef Medline

Tan J, Savigner A, Ma M, Luo M (2010) Odor information processing by the olfactory bulb analyzed in gene-targeted mice. Neuron 65:912-926. CrossRef Medline

Tukker JJ, Lasztóczi B, Katona L, Roberts JD, Pissadaki EK, Dalezios Y, Márton L, Zhang L, Klausberger T, Somogyi P (2013) Distinct dendritic arborization and in vivo firing patterns of parvalbumin-expressing basket cells in the hippocampal area ca3. J Neurosci 33:6809-6825. CrossRef Medline

Wellis DP, Scott JW (1990) Intracellular responses of identified rat olfactory bulb interneurons to electrical and odor stimulation. J Neurophysiol 64: 932-947. Medline

Westfall PH (2011) On using the bootstrap for multiple comparisons. J Biopharm Stat 21:1187-1205. CrossRef Medline

Westfall PH, Young SS (1993) Resampling-based multiple testing: examples and methods for p-value adjustment. New York: Wiley.

Wienisch M, Murthy VN (2016) Population imaging at subcellular resolution supports specific and local inhibition by granule cells in the olfactory bulb. Sci Rep 6:29308. CrossRef Medline

Woolf TB, Shepherd GM, Greer CA (1991) Local information processing in dendritic trees: Subsets of spines in granule cells of the mammalian olfactory bulb. J Neurosci 11:1837-1854. Medline

Zelles T, Boyd JD, Hardy AB, Delaney KR (2006) Branch-specific ca ${ }^{2+}$ influx from na+-dependent dendritic spikes in olfactory granule cells. J Neurosci 26:30-40. CrossRef Medline

Zimnik NC, Treadway T, Smith RS, Araneda RC (2013) Alpha (1A)adrenergic regulation of inhibition in the olfactory bulb. J Physiol 591: 1631-1643. CrossRef Medline 